\title{
Macrofauna community patterns in a Chiloe Island channel used intensely for aquaculture: the ecological status of its benthic environment
}

Eduardo Hernández-Miranda ${ }^{1,2^{*}}$ (D, Romina Estrada ${ }^{1}$, Poliana Strange ${ }^{1}$, Rodrigo Veas ${ }^{2}$, M. Cristina Krautz ${ }^{2}$ and Renato A. Quiñones ${ }^{1,3}$

\begin{abstract}
Background: It is known that aquaculture may produce negative environmental effects on marine ecosystems. Southern Chile is one of the most important salmon and mussel-producing areas in the world. Here we assess the ecological status of benthic communities near farming centers in Caucahue Channel, Chiloe, which has been used intensely for salmon and mussel production for 30 years.

Methods: The macrofauna, sediments and water column were characterized at distances of 5 to $100 \mathrm{~m}$ from three salmon and three mussel-producing centers. Information was also obtained from reference sites 500 to $3000 \mathrm{~m}$ from these aquaculture farms. The macrofauna and environmental conditions during winter were analyzed using uni- and multivariate analysis and the AZTI Marine Biotic Index (AMBI) as an indicator of benthic community condition.

Results: (i) There is a high degree of spatial dissimilarity in macrofauna and environmental variables among sampling sites and types of environments (far from or near farming centers) and between the northern and southern areas of the channel; (ii) sediment structure (mean grain size and percentage of total organic matter) correlated with the observed dissimilarities in macrofauna communities; and (iii) the level of perturbation according to $A M B I$ was heterogeneous, with sites in the undisturbed/normal range to moderately disturbed/polluted.

Conclusions: We found a high spatial dissimilarity in benthic macrofauna and environmental variables among sampling sites, environmental types and between the northern and southern areas of the channel. AMBI and multivariate community-environment analysis are useful tools to define the level of perturbation of a geographic area at different spatial scales, using all the ecological information from each sample and replicates.
\end{abstract}

Keywords: Salmon farming, Mussel farming, Aquaculture environmental impact, Benthic community, AMBI, Multivariate analysis

\footnotetext{
* Correspondence: eduhernandez@udec.cl

${ }^{1}$ Interdisciplinary Center for Aquaculture Research (INCAR), Universidad de Concepción, O’Higgins, 1695 Concepción, Chile

2Laboratorio de Investigación en Ecosistemas Acuáticos (LInEA), Facultad de Ciencias Naturales \& Oceanográficas, Universidad de Concepción,

Concepción, Chile

Full list of author information is available at the end of the article
}

(c) The Author(s). 2021 Open Access This article is licensed under a Creative Commons Attribution 4.0 International License, which permits use, sharing, adaptation, distribution and reproduction in any medium or format, as long as you give appropriate credit to the original author(s) and the source, provide a link to the Creative Commons licence, and indicate if changes were made. The images or other third party material in this article are included in the article's Creative Commons licence, unless indicated otherwise in a credit line to the material. If material is not included in the article's Creative Commons licence and your intended use is not permitted by statutory regulation or exceeds the permitted use, you will need to obtain permission directly from the copyright holder. To view a copy of this licence, visit http://creativecommons.org/licenses/by/4.0/ 


\section{Background}

Benthic habitats sustain diverse communities composed of species with distinct responses to natural and anthropogenic stress [1]. Benthic macrofauna have many features that make them useful for assessing environmental quality [2-7]. Among these are sedentary species with low mobility, many of them highly sensitive to perturbation. These species have life cycles that range from months to years, which facilitates identifying environmental effects for long periods of time and in specific locations. Consequently, the study of changes in the community structure of benthic macrofauna has become a useful tool in assessing anthropogenic effects on aquatic ecosystems [8-11]. For a proper interpretation of the observed community patterns, it is important to know other aspects of the species such as ecology, life history and sensitivity to pollution, because some of these features could mask the effects of perturbation [12]. For instance, indirect development (i.e. pelagic larval stages) could result in impacts being masked by recruitment coming from outside the impacted area, and long life-cycles of some species could result in slow responses to some specific perturbations.

The effects of increased organic matter content in marine sediments on benthic communities have been widely documented and generally include quantitative and qualitative structural changes [2, 13-15]. Pearson \& Rosenberg [2] developed a model for changes in species richness, abundance and biomass of benthic macrofauna according to the level of organic enrichment of sediments. They argued that continued increases in organic matter over time modify community structure (loss of diversity), with a final persistence of tolerant and opportunistic species until the environment becomes anoxic and eventually produces the complete loss of species (azoic environment).

Different environmental effects have been reported in relation to salmon and mussel farms, the most important being the increased flow of organic matter to the seafloor [16-21], which accumulates in sediments and later oxidizes [22-24], resulting in a decrease in dissolved oxygen in the water column and also in the oxidation-reduction potential of the sediments [25, 26]. If the flow of organic matter is sufficiently high, it can increase the levels of hydrogen sulfide and ammonium in the sediments due to increased activity of specific groups of bacteria [26], resulting in completely anoxic and azoic environments.

There have been increasing efforts in recent years to monitor and assess the effects of aquaculture farming centers on marine ecosystems (e.g. [27]). Biological and ecological indicators have been used to assess the status of benthic communities living below or near farming centers, mainly for fish and filtering bivalves [21, 27-29].
One of the biological indicators that has provided better results is the AZTI Marine Biotic Index (AMBI), as described by [30]. AMBI aids in assessing the quality of marine sediments $[30,31]$ based on variations in benthic macrofauna communities due to environmental changes $[30,32]$. AMBI is based on the relative abundance of macrofauna species, which are assigned to five ecological groups according to their sensitivity to pollution stress or perturbation [33]. In Chile there is no official list of species included in AMBI, however, many macrofauna species living in the South Pacific are cosmopolitan or have been already identified in other ecosystems, and therefore they are classified in the AMBI taxa listing, which allows the assignment to the Ecological Groups (See also [11, 34]).

The objective of this study was to assess changes in macrofauna community structure in relation to distance from the aquaculture centers in Caucahue Channel (inner sea of Chiloe), an area used intensely for salmon culture and bivalve farming in the past 30 years. This study does not seek to quantify the ecological conditions directly beneath fish cages or mussel long-lines, but rather the general ecological condition of the Caucahue Channel. Community dissimilarity was assessed at different spatial scales, using a high spatial resolution sampling design and comparing benthic macrofauna between sampling sites near (few meters) and far (dozen of meters) from six farming centers (3 for bivalves and 3 for salmon) using uni- and multivariate ecological indicators of diversity and the biotic index AMBI as an indicator of the ecological status. We searched for the environmental variables that best explain the multivariate structure of benthic macrofauna. The general working hypothesis is that the benthic macrofauna community from sites closer to farming centers (few meters) are in poorer ecological condition (i.e. less diversity of sensitive ecological groups based on the AMBI indicator) than those far (dozens of meters) from farming centers.

\section{Methods}

\section{Study area}

The study area was Caucahue Channel $\left(42.12^{\circ} \mathrm{S}, 73.44^{\circ}\right.$ W), which separates Caucahue Island from Chiloé Island in southern Chile. Caucahue Channel is described as a coastal environment with two openings to the inner sea, one facing north and the other south [35, 36] (Fig. 1). There is intensive aquaculture in the channel, producing mainly mussels and salmonids. The channel receives fresh water mainly from precipitation and some discharges from freshwater runoff and domestic waste [37]. Aquaculture has been permitted in the Caucahue Channel since 1985 (www.subpesca.cl), and at present there are 55 aquaculture concessions (salmonids, mollusks and 


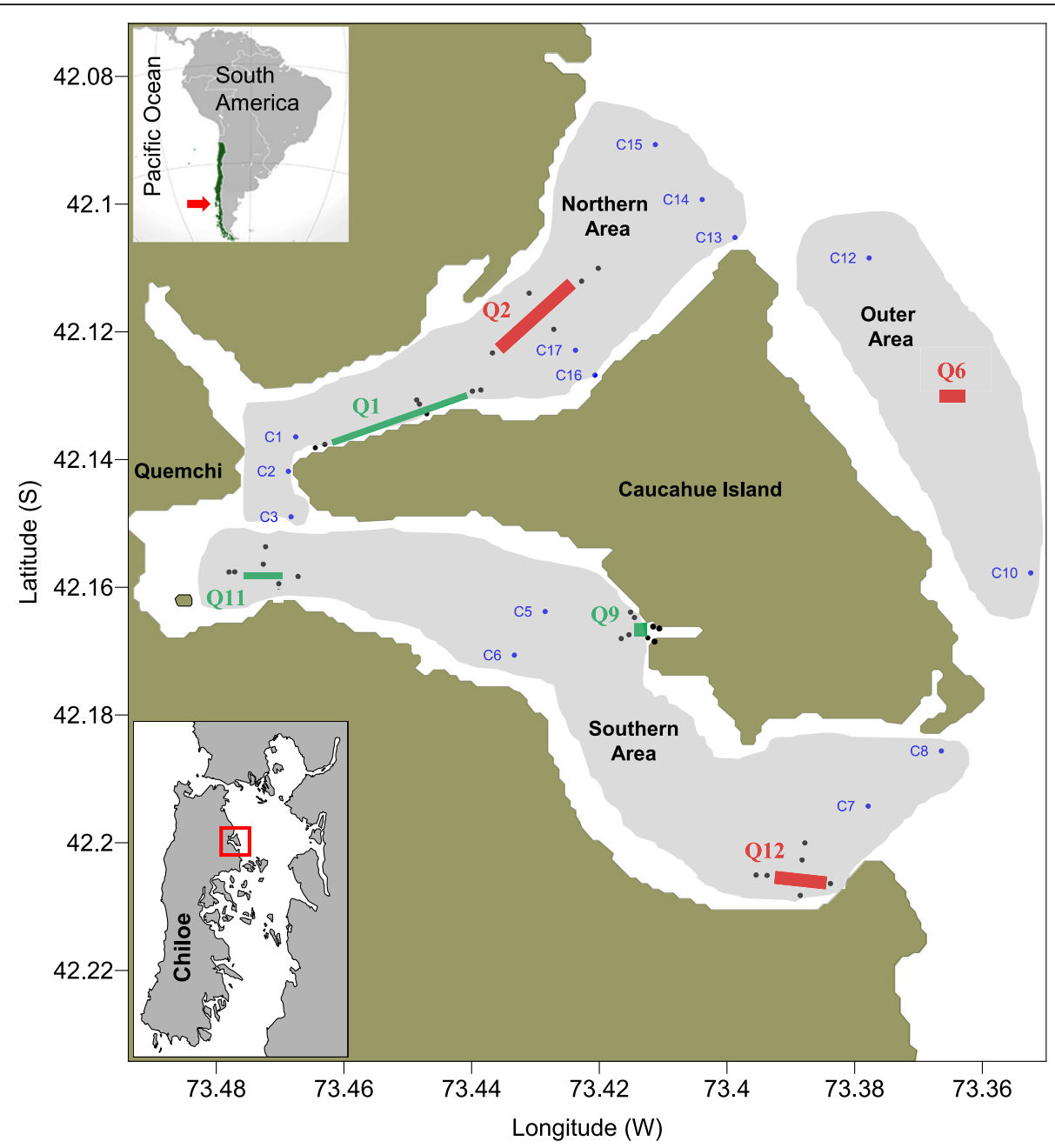

Fig. 1 Caucahue Channel showing sampling sites. Q sites are near active aquaculture centers (green area with black dots = mussel farm, red area with black dots = salmon farm). Blue dots ( $C$ sites) represent reference sites far from active aquaculture centers. Grey zones correspond to northern, southern and outer areas of the channel

seaweeds) occupying an area of approximately 843.81 ha. Of these, 37 produce mollusks (570.14 ha), mainly mussels, 13 produce salmonids (258.47 ha) and 5 produce algae (15.2 ha). The total area of the channel is approximately $42.32 \mathrm{~km}^{2}$, of which $20 \%$ or about $8.44 \mathrm{~km}^{2}$ are allocated for aquaculture concessions. This study incorporates biological and environmental information near six active aquaculture farms, three for mussels (MYT sites) Q1 (43.11 ha), Q9 (15.54 ha), Q11 (14.64 ha) and three for salmonids (SAL sites) Q2 (29.76 ha), Q6 (12.57 ha) and Q12 (50.0 ha) (Fig. 1).

\section{Benthic and water column sampling}

Sampling was conducted between June 21 and 24, 2014 (beginning of the austral winter) on board the L/M Dr. Jürgen Winter (Austral University of Chile). The samples were collected near six farming centers (Q1, Q2, Q6, Q9, Q11 and Q12) (Fig. 1). The distances between sampling sites and mussel centers were between 5 and $50 \mathrm{~m}$, while the distances from salmonid farms were between 25 and $100 \mathrm{~m}$ (Fig. 2). There were also 14 reference sampling sites (REF sites) far from active farming centers (between 500 and $3000 \mathrm{~m}$ ) in Caucahue Channel and beyond the channel in the inner sea (Figs. 1, 2). The REF sites were selected after conducting a complete assessment of the channel. The following criteria were used for selecting the REF sites: (i) generate spatial gradients in relation to each of the six selected aquaculture farms, (ii) the gradient should move away from other active aquaculture farms, and (iii) to characterize the whole Caucahue Channel (See Figs. 1, 2). There are other sea uses of Caucahue Channel in addition to aquaculture activity, including an artisan fishing port, artisanal fisheries, wastewater discharge from a small town and small craft navigation [37]. 

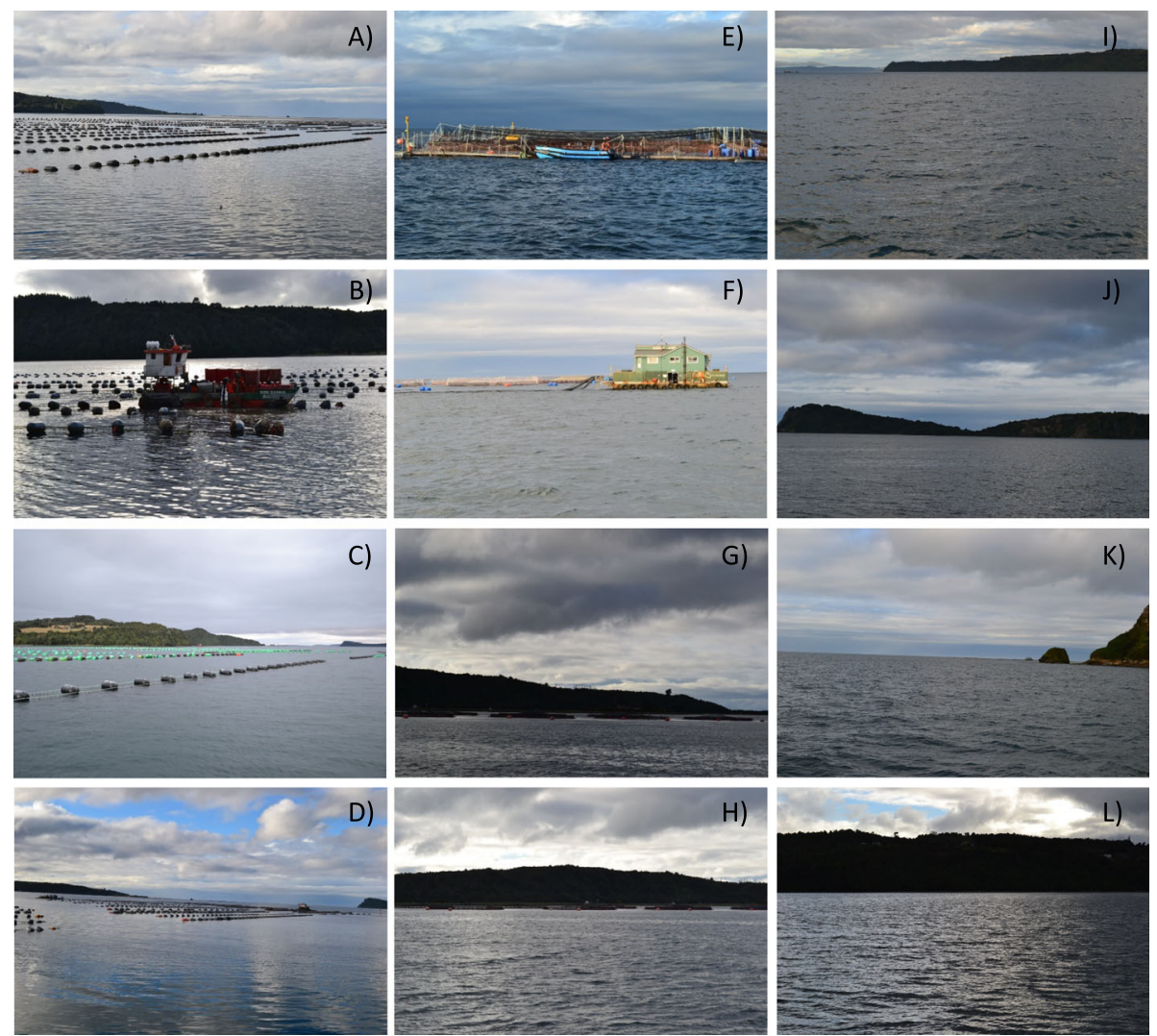

Fig. 2 Photographs of Caucahue Channel showing gradients of distances from active aquaculture farms and surrounding areas of references sampling sites. a-d $Q$ sites near and far from active mussel farms, $\mathbf{e}-\mathbf{h}) \mathrm{Q}$ sites near and far from active salmon farms, $\mathbf{i}-\mathbf{I} \mathbf{C}$ references sites far from active aquaculture farms

Sediment samples were gathered with a van Veen grab sampler with a bite of $0.051 \mathrm{~m}^{2}$. Four replicates were taken at each site, three to analyze macrofauna and one to determine total organic matter content (\%TOM) and sediment grain size. The macrofauna samples were preserved in the field with $4 \%$ formalin buffered with borax. The samples for grain size and \%TOM were kept in cold storage until analysis. Due to a failure in the Redox potential sensor for sediments, these data were discarded. Seawater samples were collected with a Niskin bottle from the surface $(0 \mathrm{~m})$ and near the seafloor $(1-2 \mathrm{~m}$ above the bottom) at all sites. Temperature $\left({ }^{\circ} \mathrm{C}\right)$, salinity, dissolved oxygen concentration $\left(\mathrm{mg} \mathrm{L}^{-1}\right)$, redox potential $(\mathrm{mV}), \mathrm{pH}$, conductivity $\left(\mathrm{mS} \mathrm{cm}^{-1}\right)$ and total dissolved solids (TDS; $\mathrm{g} \mathrm{L}^{-1}$ ) were recorded using a YSI556 MPS multiparameter probe.

The sediment samples obtained for macrofauna analysis were sieved in the laboratory with a $500-\mu \mathrm{m}$ sieve $[38,39]$. The sieved material was placed in plastic flasks and preserved in $96 \%$ ethanol. All organisms found in the samples were separated with the aid of a stereomicroscope and identified to the lowest taxonomic level possible. Total biomass per species/taxon was estimated as wet weight with an electronic analytical scale with a precision of $0.0001 \mathrm{~g}$. Sediment grain size was determined by automatic sifting through a series of geological sieves (from $2 \mathrm{~mm}$ to $63 \mu \mathrm{m}$ mesh size) [40]. Mean grain size and sediment sorting were calculated by the moment method with the GRADISTAT v8.0 program [41]. Total organic matter content in sediments (\%TOM) was estimated as the percentage lost by sediment after calcination at $550{ }^{\circ} \mathrm{C}$ for $4 \mathrm{~h}[42]$.

\section{Data analysis}

To determine macrofauna community dissimilarity in Caucahue Channel at different spatial scales, the factors channel area (AREA), environment (ENV), farming center (CENTER) and sampling site (SITE) were assessed by multivariate analyses. The AREA factor was used to compare sampling sites in the northern, southern and outer areas of the channel (See Fig. 1, Table 1). The ENV factor was assessed by analyzing the role of proximity to farming centers, with three assigned levels: salmonids (SAL), mussels (MYT), and reference (REF). The CENTER factor was assessed by assigning the sites to respective farming centers (Q1, Q2, Q6, Q9, Q11, Q12) 
Table 1 Classification of sampling sites according to factor analysis performed with PERMANOVA. The factors were channel area (AREA), environment (ENV), farming center (CENTER) and sampling sites (SITE). $\mathrm{Q}_{\mathrm{i}}$ corresponds to aquaculture sites, REF corresponds to reference sites. See also Fig. 1 and Methods for details

\begin{tabular}{|c|c|c|c|c|c|c|c|}
\hline \multirow{2}{*}{$\begin{array}{l}\text { Factors } \\
\text { AREA }\end{array}$} & \multicolumn{7}{|l|}{ Levels } \\
\hline & \multicolumn{2}{|l|}{ Northern area } & \multicolumn{2}{|c|}{ Southern area } & \multicolumn{3}{|l|}{ Outer area } \\
\hline & \multicolumn{2}{|l|}{$\begin{array}{l}\text { Q1, Q2, } \\
\mathrm{C} 1, \mathrm{C} 2, \mathrm{C} 3, \mathrm{C} 13, \\
\mathrm{C} 14, \mathrm{C} 15, \mathrm{C} 16, \mathrm{C} 17\end{array}$} & \multicolumn{2}{|c|}{$\begin{array}{l}\text { Q9, Q11, Q12, } \\
\text { C5, C6, C7, C8 }\end{array}$} & \multicolumn{3}{|l|}{$\begin{array}{l}\text { Q6, } \\
\text { C10, C12 }\end{array}$} \\
\hline \multirow[t]{2}{*}{ ENV } & \multicolumn{2}{|l|}{ Salmon farms } & \multicolumn{2}{|c|}{ Mytilid farms } & \multicolumn{3}{|l|}{ Reference sites } \\
\hline & \multicolumn{2}{|l|}{ Q2, Q6, Q12 } & \multicolumn{2}{|c|}{ Q1, Q9, Q11 } & \multicolumn{3}{|c|}{$\begin{array}{l}\mathrm{C} 1, \mathrm{C2}, \mathrm{C} 3, \mathrm{C} 5, \mathrm{C} 6, \mathrm{C} 7, \mathrm{C} 8, \mathrm{C10} \\
\mathrm{C} 12, \mathrm{C} 13, \mathrm{C} 14, \mathrm{C} 15, \mathrm{C} 16, \mathrm{C} 17\end{array}$} \\
\hline CENTER & Q1 & Q2 & Q6 & Q9 & Q11 & Q12 & REF \\
\hline SITE & $\begin{array}{l}\text { Q1-1, Q1-3, Q1-4, } \\
\text { Q1-5, Q1-6, Q1-7, } \\
\text { Q1-8 }\end{array}$ & $\begin{array}{l}\text { Q2-2, Q2-3, } \\
\text { Q2-5, Q2-6, } \\
\text { Q2-7 }\end{array}$ & Q6-1 & $\begin{array}{l}\text { Q9-1, Q9-2, Q9-3, } \\
\text { Q9-4, Q9-5, Q9-6, } \\
\text { Q9-7, Q9-8 }\end{array}$ & $\begin{array}{l}\text { Q11-1, Q11-3, } \\
\text { Q11-4, Q11-6, } \\
\text { Q11-7, Q11-8 }\end{array}$ & $\begin{array}{l}\text { Q12-1, Q12-3, } \\
\text { Q12-4, Q12-5, } \\
\text { Q12-6, Q12-8 }\end{array}$ & $\begin{array}{l}\mathrm{C} 1, \mathrm{C} 2, \mathrm{C} 3, \mathrm{C} 5, \mathrm{C} 6, \mathrm{C} 7, \\
\mathrm{C} 8, \mathrm{C} 10, \mathrm{C} 12, \mathrm{C} 13, \mathrm{C} 14, \\
\mathrm{C} 15, \mathrm{C} 16, \mathrm{C} 17\end{array}$ \\
\hline
\end{tabular}

and reference sites (REF). The SITE factor was used to compare sampling sites independent of their proximity to farming centers or the area to which they belong (See Table 1 for details). Similarity measures for benthic macrofauna (using all identified species) were determined using abundance data (ind. $0.051 \mathrm{~m}^{-2}$ ) and biomass ( $\mathrm{g}$ $0.051 \mathrm{~m}^{-2}$ ), based on the Bray-Curtis index with fourth root transformed data. The fourth root transformation was applied to remove the greater weight of dominant species from the analysis and to give more importance to less common species [43]. A PERMDISP ("Permutational Multivariate Dispersion Analysis") was applied to assess the homogeneity of multivariate dispersion. The statistical differences in benthic macrofauna for the spatial factors of the analysis were assessed by a PERM ANOVA ("Permutational Multivariate Analysis of Variance"). A posteriori pair-wise analysis was applied when the PERMANOVA found significant differences $(p<$ $0.05)$ for any factor. The statistical differences in environmental conditions in Caucahue Channel for the aforementioned spatial factors were estimated based on the set of variables obtained in the sediments and the water column. Distance measurements of the environmental variables were obtained based on Euclidian distances with normalized data. An unrestricted model was used for all the analyses, with 9999 permutations. The multivariate analyses were performed using the statistical software PRIMER v7 and PERMANOVA+ [44-47].

Spatial dissimilarity/distances for biological and environmental variables were represented graphically with non-metric multidimensional scaling ( $n$ MDS), which was obtained with resemblance measures/transformations similar to those described for the PERM ANOVA analysis. The $n$ MDS were represented by the bubble plot method that incorporates the most representative species of the community (obtained by SIMPER analysis) and the most important environmental variables (obtained by DISTLM analysis). The
SIMPER ("Similarity Percentages Analysis") identifies the percentage contribution of different taxa. The DISTLM ("Distance-based Linear Model") determines which environmental variable or sets of variables are significantly related to multivariate community ordination (e.g. abundance and biomass), using distancebased linear models. The Best procedure, with 9999 iterations, and the Bayesian information criterion for model selection (BIC $[43,48]$ ) were used to select the environmental variables that best explained the multivariate distribution of the community. The univariate indices of species richness (S), Shannon-Wiener diversity $\left(\mathrm{H}^{\prime}\right)$, Simpson dominance $(\mathrm{D})$, and Pielou evenness $\left(J^{\prime}\right)$ were calculated based on all replicates for the ENV factor. Total abundance and biomass ind/g $0.153 \mathrm{~m}^{-2}$ for ENV factor were standardized per sampling site (which incorporates all replicates per site). The univariate indices were estimated with PRIMER v7 software [46, 49].

The degree of environmental condition (i.e. Ecological Status) was analyzed with the AMBI indicator [30] with software v5.0 (http://ambi.azti.es) [31, 5052]. Some modifications were incorporated in the estimations because some taxa were not initially assigned to any ecological group. The modifications consisted of assigning these taxa to an ecological group according to their taxonomic relationship (genus or family) using two designation criteria (i) the best ecological group (AMBI-1) and (ii) the poorest ecological group (AMBI-2) to which it could belong (See [38] for details). The AMBI coefficient/index (BC/BI) has a score from 0 (Normal/Undisturbed/ High Status) to 7 (Azoic/Extremely disturbed/Bad Status) [53]. Finally, the values estimated for the AMBI were incorporated with color range in the $n \mathrm{MDS}$ analysis of macrofauna, to visualize whether spatial community groupings (AREA, ENV, CENTER and SITE) have similar ecological status for this bio-indicator. 


\section{Results}

\section{Macrofauna community diversity}

A total of 170 taxa/species were identified in Caucahue Channel, representing 86 families, 51 orders, 24 classes and 12 phyla. Mean total abundance was 671.8 ( \pm 438.3) and $187.8( \pm 535.5)$ ind $/ 0.153 \mathrm{~m}^{2}$ (with and without mytilids) and average total biomass was 12.3 ( \pm 12.9) and 11.1 ( \pm 64.6$) \mathrm{g} / 0.153 \mathrm{~m}^{2}$ (with and without mytilids). Excluding mytilids, the most abundant groups were annelids (60\%), nematodes (13\%) and other mollusks (12\%), while the most important in terms of biomass were annelids (35\%), echinoderms (33\%) and other mollusks (17\%). Figure 3 shows the mean values of total abundance, total biomass, species richness, diversity, evenness, dominance and AMBI, according to the ENV factor. Total abundance and total biomass of benthic macrofauna were lowest at SAL sites (Fig. 3a, b). Species richness was slightly higher at REF sites (Fig. 3c). Shannon-Wiener diversity and Pielou evenness were slightly lower at MYT sites, and Simpson dominance was highest at MYT sites (Fig. 3d-f).

The PERMDISP analysis had a value of $P$ (perm) $<0.05$ for macrofauna density and biomass (fourth root transformation) only among sampling sites. A posteriori pairwise analysis found a significant difference between 28.6\% (abundance) and $42.8 \%$ (biomass) comparisons. These percentages, mainly associated with site Q6 (71.4\% of the total pair-wise test), indicate that there is
A)

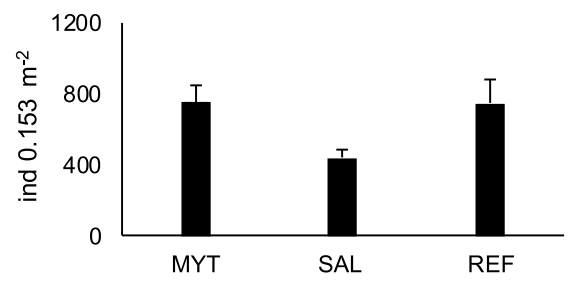

C)

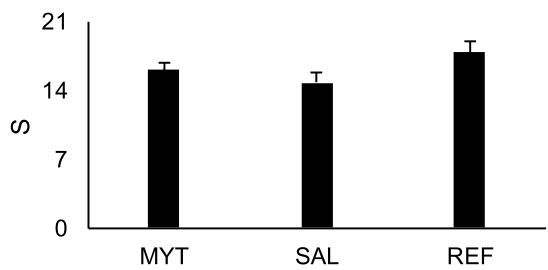

E)

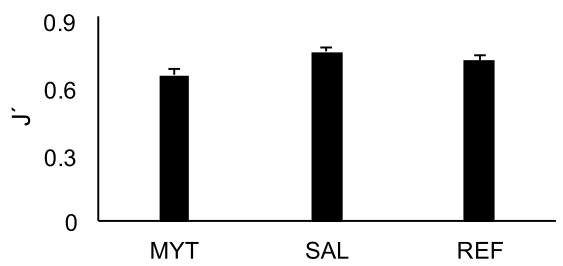

G)

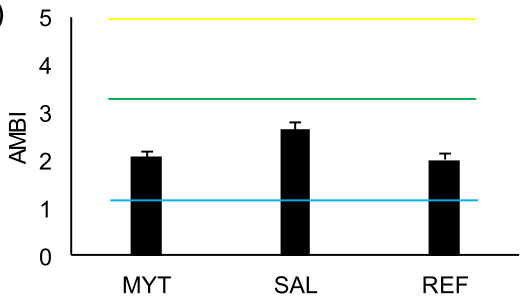

B)

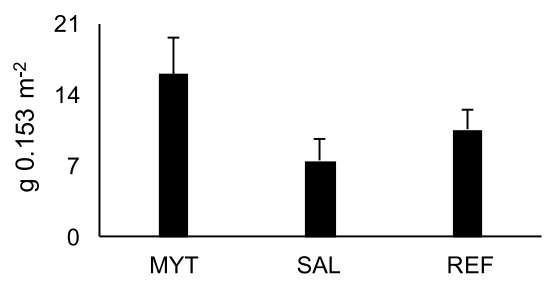

D)

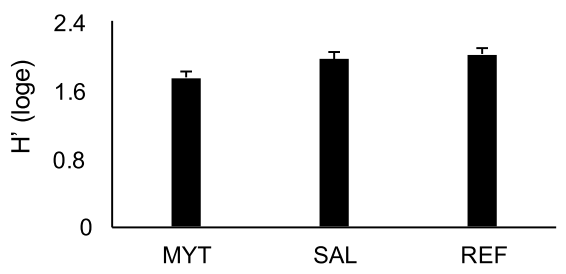

F)

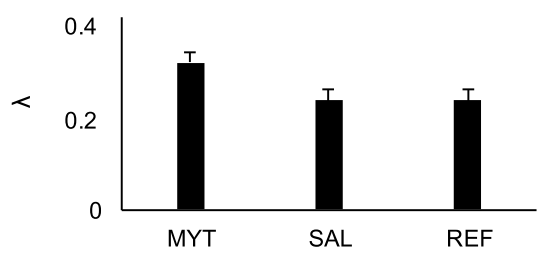

H)

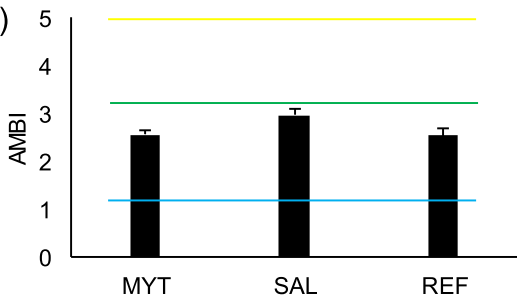

Fig. 3 Average values (standard error) for the ENV factor of total abundance (a), total biomass (b), species richness (c), Shannon-Wiener diversity (d), Pielou evenness (e), Simpson dominance $(\mathbf{f})$, AMBI-1 $(\mathbf{g})$, AMBI-2 (h). The solid line in $\mathbf{g}$ and $\mathbf{h}$ represents the cutoff values for levels of disturbance according to AMBI: Undisturbed (blue, 1.2), Slightly disturbed (green, 3.3) and Moderately disturbed (yellow, 5.0) 
no multivariate overdispersion in the abundance and biomass data, which can thus be assessed by PERM ANOVA.

Figure 4 shows the $n \mathrm{MDS}$ analysis of macrofauna abundance and biomass with the Bray-Curtis resemblance measure and fourth root-transformed data. The REF sites (green) are grouped in the center of the $n \mathrm{MDS}$ for abundance and biomass, with the centroids in SAL and MYT sites shifted to the right (Fig. 4a, b). The groupings tend to separate into specific $n$ MDS zones according to their proximity to aquaculture farms (e.g. Q12 to the right and Q2 to the left; Fig. 4c, d), as was observed for all the sampling sites individually (e.g. replicates from a site with the same symbols; Fig. 4e, f). The PERMANOVA analysis for abundance and biomass fourth roottransformed yielded $P$ (perm) values of $<0.05$ for the factors AREA, ENV, CENTER and SITE (Table 2). Almost all the pair-wise analyses yielded $P($ perm $)$ values $<0.05$.

\section{Multivariate diversity and environmental variables}

The PERMDISP analysis for the set of environmental variables for sediments and the water column at the sampling sites had a $P$ (perm) value of $0.709, \mathrm{~F}: 2.27 \mathrm{df}$, 6 , 45 , because of which the PERMANOVA analysis was

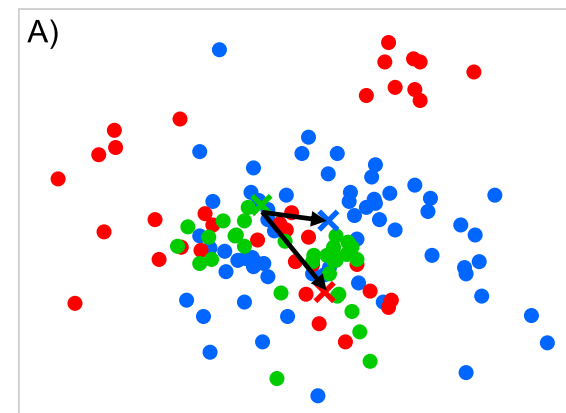

Stress: 0.23

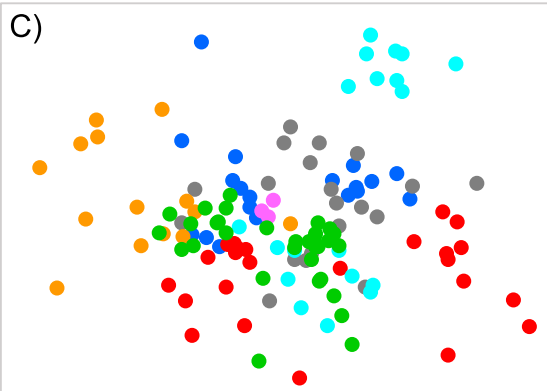

Stress: 0.23

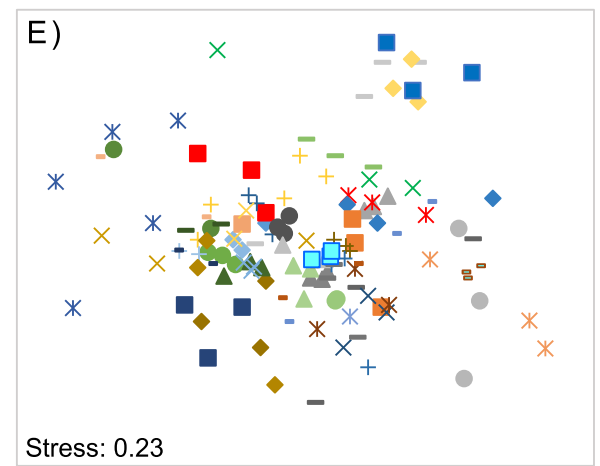

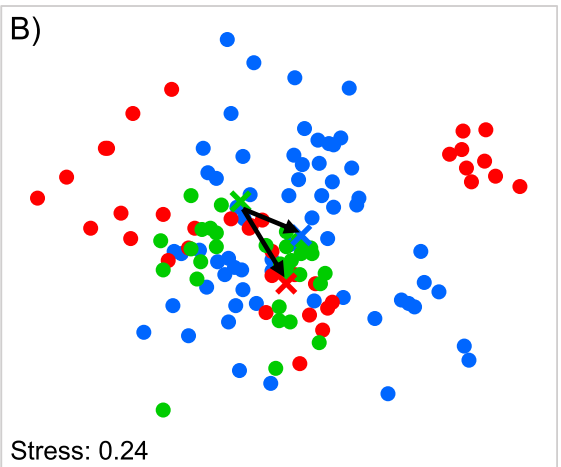

Stress: 0.24
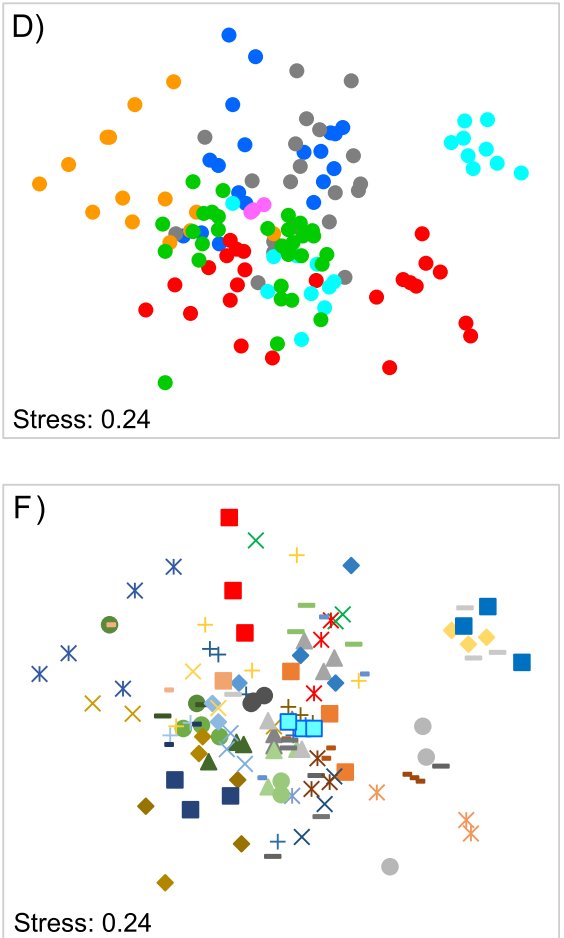

Fig. 4 nMDS for benthic macrofauna in Caucahue Channel fourth-root transformation of Bray-Curtis index. $\mathbf{a}, \mathbf{b}$ factor ENV; $\mathbf{c}, \mathbf{d}$ factor CENTER; $\mathbf{e}, \mathbf{f}$ factor SITE. $\mathbf{a}, \mathbf{c}$, e correspond to abundance, and $\mathbf{b}, \mathbf{d}, \mathbf{f}$ ) to biomass. In A and B, crosses indicate centroids for the three groupings: MYT with blue circles, SAL with red and REF with green. In $\mathbf{c}$ and $\mathbf{d}$ each color represents a farm (Q1: blue, Q9: red, Q11: grey, Q2: orange, Q12: light blue, Q6: pink, REF: green). In $\mathbf{e}$ and $\mathbf{f}$ each similar symbol/color represents a sampling site 
Table 2 Output of PERMANOVA main tests for (A) abundance fourth-root transformed with the Bray-Curtis index, (B) biomass fourth-root transformed with the Bray-Curtis index. Factors of analysis were channel area (AREA), environment (ENV), farming center (CENTER) and sampling site (SITE). $P$ (perm) $<0.05$ values are in bold

\begin{tabular}{|c|c|c|c|c|c|c|}
\hline Source & d.f. & SS & MS & Pseudo-F & $P$ (perm) & Unique perms \\
\hline \multicolumn{7}{|l|}{ A) } \\
\hline AREA & 2 & 22.628 & 11.314 & 3.8018 & 0.0001 & 9893 \\
\hline Res & 128 & 380.920 & 2.976 & & & \\
\hline Total & 130 & 403.550 & & & & \\
\hline ENV & 2 & 26.665 & 13.332 & 4.5281 & 0.0001 & 9848 \\
\hline Res & 128 & 376.890 & 2.944 .4 & & & \\
\hline Total & 130 & 403.550 & & & & \\
\hline CENTER & 6 & 80.450 & 13.408 & 5.1458 & 0.0001 & 9806 \\
\hline Res & 124 & 323.100 & 2.605 .7 & & & \\
\hline Total & 130 & 403.550 & & & & \\
\hline SITE & 46 & 274.810 & 5.974 .2 & 3.8981 & 0.0001 & 9564 \\
\hline Res & 84 & 128.740 & 1.532 .6 & & & \\
\hline Total & 130 & 403.550 & & & & \\
\hline \multicolumn{7}{|l|}{ B) } \\
\hline AREA & 2 & 24.985 & 12.492 & 3.7757 & 0.0001 & 9866 \\
\hline Res & 128 & 423.500 & 3.308 .6 & & & \\
\hline Total & 130 & 448.490 & & & & \\
\hline ENV & 2 & 27.043 & 13.522 & 4.1067 & 0.0001 & 9862 \\
\hline Res & 128 & 421.450 & 3.292 .5 & & & \\
\hline Total & 130 & 448.490 & & & & \\
\hline CENTER & 6 & 82.509 & 13.752 & 4.6592 & 0.0001 & 9747 \\
\hline Res & 124 & 365.980 & 2.951 .4 & & & \\
\hline Total & 130 & 448.490 & & & & \\
\hline SITE & 46 & 299.090 & 6.502 & 3.6559 & 0.0001 & 9558 \\
\hline Res & 84 & 149.390 & 1.778 .5 & & & \\
\hline Total & 130 & 448.490 & & & & \\
\hline
\end{tabular}

applied. The PERMANOVA analysis yielded $P($ perm $)$ values $<0.05$ for the factors AREA, ENV and CENTER (Table 3). As with the abundance and biomass data, the pair-wise tests yielded $P$ (perm) values of $<0.05$ for most of the analyses. The $n$ MDS analysis yielded a similar pattern to those of macrofauna for AREA, ENV and CENT ER (Fig. 5). The mean values for farming centers (CENTER) and reference sites (REF) for the environmental variables are shown in Table 4. The DISTLM analysis for macrofauna abundance and biomass as a function of the environmental variables found a series of significant variables (Table 5a, b), although according to the BIC the best fit in both cases was with mean grain size (Table 6a, b). The second-best model for abundance included surface $\mathrm{pH}$ and Sorting, and the second-best model for biomass also included \%TOM (Table 6a, b).
Table 3 Output of the main PERMANOVA tests for water column variables. Factors of analysis were channel area (AREA), environment (ENV) and farming center (CENTER). $P($ perm) $<0.05$ values are in bold

\begin{tabular}{llllccl}
\hline Source & d.f. & SS & MS & Pseudo-F & $\boldsymbol{P}$ (perm) & Unique perms \\
\hline AREA & 2 & 155.75 & 77.875 & 4.1692 & $\mathbf{0 . 0 0 0 1}$ & 9906 \\
Res & 49 & 915.25 & 18.679 & & & \\
Total & 51 & 1071 & & & & \\
ENV & 2 & 102.29 & 51.147 & 2.5872 & $\mathbf{0 . 0 0 0 9}$ & 9894 \\
Res & 49 & 968.71 & 19.769 & & & \\
Total & 51 & 1071 & & & & \\
CENTER & 6 & 326.6 & 54.433 & 3.2906 & $\mathbf{0 . 0 0 0 1}$ & 9863 \\
Res & 45 & 744.4 & 16.542 & & & \\
Total & 51 & 1071 & & & & \\
\hline
\end{tabular}




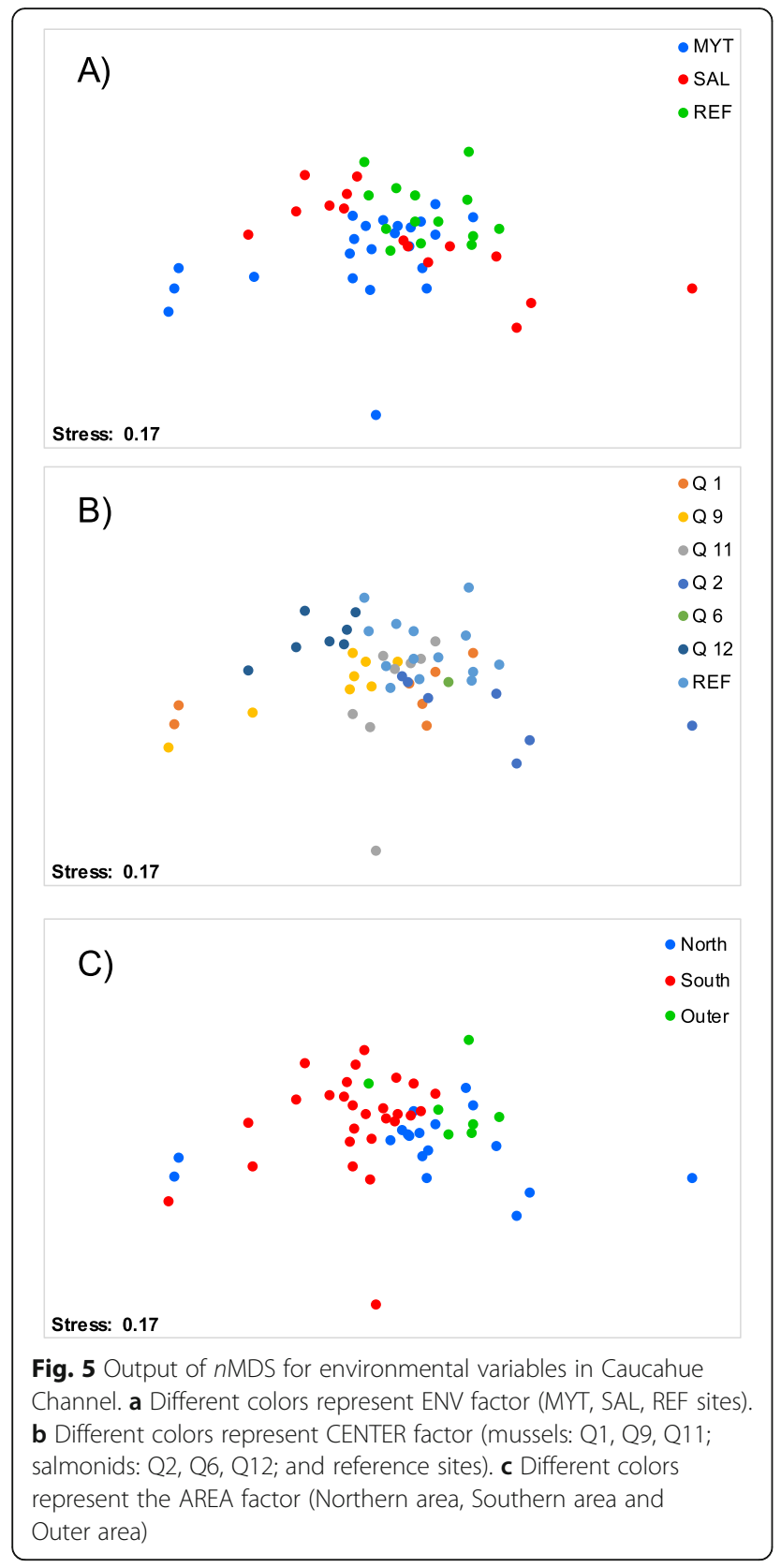

By overlapping species bubble abundance-plots with $n$ MDSs, Fig. 6 shows the taxa that contribute most to the dissimilarity between environmental types (ENV) according to the SIMPER analysis (See also Tables 7 and 8). The most representative taxa close to the mussel farming centers (MYT) were Ophiuroidea, Nematoda, Ampharetidae, Chaetozone sp., Cirrophorus sp. and Prionospio sp., while the families Spionidae and Cirratulidae were dominant near salmonid farming centers (SAL). The families Cirratulidae, Ampharetidae and Paraonidae were predominant in the reference sites (REF). Overlaying the variables selected by the DISTLM analysis (Tables 5 and 6) with the $n$ MDS plot obtained from environmental variables showed that MYT sites had higher mean grain size and sorting values, and lower $\mathrm{pH}$ values (Fig. 7).

\section{Ecological status}

Figure $8 \mathrm{a}$ and $\mathrm{b}$ show the two AMBI scenarios obtained for the best (AMBI-1) and poorest (AMBI-2) ecological group assignment based on the macrofauna abundance replicates using a color scale (i.e. finer spatial scale observation data). No defined spatial pattern was observed for the AMBI index as a function of environment (ENV) or center type (CENTER) or within the channel areas (AREA), although the reference sites (triangles) showed the best level of ecological status classification (blue and green symbols) with respect to MYT and SAL sites (squares and circles). Some MYT and SAL sites also showed high scores for this classification in some sampling sites. Values for the replicates based on AMBI-1 and 2 were between 0.9 and 3.6 for REF sites, 0.6 and 3.9 for MYT sites, and 0.9 and 4.9 for SAL sites. Following Muxica et al. [53], REF and MYT sites can be categorized in the range from the upper limit of undisturbed to the lower limit of moderately disturbed classification (from impoverished to transitional to polluted benthic community health), while SAL sites can be categorized from the upper limit of undisturbed to the upper limit of moderately disturbed classification (from impoverished to polluted benthic community health). Figure $3 \mathrm{~g}$ and $h$ show the average AMBI- 1 and 2 values for the three types of environment (REF, MYT and SAL), considering the two scenarios of species assignment, "best" (Fig. 3g) and "poorest" (Fig. 3h). The results are broadly similar in the two cases, and the three types of environments are classified globally as slightly disturbed (i.e., AMBI range $<3$ but $>2$ on average in both scenarios), SAL sites having the poorest condition on average (Fig. 3g, h).

\section{Discussion}

Macrofauna community and environmental variables

There is increasing interest in and need for defining adequate environmental indicators to determine the status of marine ecosystems (e.g. [8, 9, 11, 54]). It has been shown that aquaculture can have negative effects on receiving environments, especially in relation to changes in the benthic substrate [55-60]. Several authors have reported that the environmental condition that best describes the ecological impact of aquaculture is organic enrichment under culture centers, and the consequent physical-chemical changes in sediments and the fauna that inhabit sediments (e.g. [26, 28, 56, 57]). It has been reported that the effects of organic enrichment on benthic ecosystems decrease with distance from the source of the perturbation [2]. It was found that near shellfish 
Table 4 Average values $( \pm D E)$ of environmental variables recorded at surface and deeper strata of each sampling site in Caucahue Channel. REF = references sites; Q1, Q9, Q11 = mussel farms; Q2, Q6, Q12 = salmon farms

\begin{tabular}{|c|c|c|c|c|c|c|c|}
\hline Variable & REF & Q 1 & Q 9 & Q 11 & Q 2 & Q 6 & Q 12 \\
\hline Depth (m) & $56.57 \pm 37.41$ & $41 \pm 0$ & $50 \pm 0$ & $26 \pm 0$ & $50 \pm 0$ & 30 & $77 \pm 0$ \\
\hline Surface Temperature $\left({ }^{\circ} \mathrm{C}\right)$ & $10.53 \pm 0.15$ & $10.51 \pm 0.07$ & $10.62 \pm 0.06$ & $10.55 \pm 0.02$ & $10.14 \pm 0.24$ & 10.49 & $10.73 \pm 0.08$ \\
\hline Bottom Temperature $\left({ }^{\circ} \mathrm{C}\right)$ & $10.54 \pm 0.12$ & $10.61 \pm 0.13$ & $10.78 \pm 0.13$ & $10.73 \pm 0.14$ & $10.42 \pm 0.14$ & 10.63 & $10.81 \pm 0.11$ \\
\hline Surface Conductivity (mS/cm) & $36.09 \pm 0.21$ & $35.92 \pm 0.16$ & $35.81 \pm 0.32$ & $35.52 \pm 1.12$ & $35.16 \pm 0.58$ & 36.04 & $36.18 \pm 0.10$ \\
\hline Bottom Conductivity (mS/cm) & $36.24 \pm 0.09$ & $36.23 \pm 0.12$ & $36.37 \pm 0.13$ & $36.4 \pm 0.14$ & $35.88 \pm 0.54$ & 36.33 & $36.48 \pm 0.15$ \\
\hline Surface TDS (g/l) & $32.43 \pm 0.12$ & $32.28 \pm 0.09$ & $32.09 \pm 0.31$ & $31.9 \pm 0.99$ & $31.92 \pm 0.34$ & 32.41 & $32.3 \pm 0.06$ \\
\hline Bottom TDS (g/l) & $32.53 \pm 0.06$ & $32.47 \pm 0.04$ & $32.45 \pm 0.07$ & $32.52 \pm 0.03$ & $32.5 \pm 0.02$ & 32.55 & $32.52 \pm 0.05$ \\
\hline Surface Salinity & $32.49 \pm 0.14$ & $32.33 \pm 0.11$ & $32.13 \pm 0.34$ & $31.91 \pm 1.10$ & $31.81 \pm 0.49$ & 32.46 & $32.39 \pm 0.05$ \\
\hline Bottom Salinity & $32.59 \pm 0.09$ & $32.55 \pm 0.05$ & $32.54 \pm 0.07$ & $32.61 \pm 0.03$ & $32.58 \pm 0.04$ & 32.64 & $32.62 \pm 0.06$ \\
\hline Surface Dissolved Oxygen (mg/l) & $7.53 \pm 0.37$ & $7.04 \pm 0.85$ & $7.38 \pm 0.52$ & $7.56 \pm 0.47$ & $7.17 \pm 0.22$ & 6.96 & $7.46 \pm 0.46$ \\
\hline Bottom Dissolved Oxygen (mg/l) & $6.77 \pm 0.55$ & $6.55 \pm 0.76$ & $6.84 \pm 0.57$ & $6.48 \pm 0.48$ & $6.52 \pm 0.21$ & 6.63 & $6.81 \pm 0.53$ \\
\hline Surface pH & $8.36 \pm 0.05$ & $8.34 \pm 0.06$ & $8.25 \pm 0.02$ & $8.32 \pm 0.05$ & $8.35 \pm 0.11$ & 8.33 & $8.17 \pm 0.08$ \\
\hline Bottom pH & $8.32 \pm 0.03$ & $8.33 \pm 0.05$ & $8.25 \pm 0.01$ & $8.33 \pm 0.04$ & $8.30 \pm 0.04$ & 8.39 & $8.19 \pm 0.03$ \\
\hline Surface Redox (mV) & $26.09 \pm 9.96$ & $28.69 \pm 4.46$ & $27.16 \pm 7.41$ & $23.88 \pm 5.64$ & $38.71 \pm 13.16$ & 34.6 & $23.39 \pm 9.64$ \\
\hline Bottom Redox (mV) & $28.75 \pm 8.15$ & $31.71 \pm 6.63$ & $24.78 \pm 4.22$ & $21.5 \pm 5.98$ & $43.83 \pm 12.75$ & 50.5 & $21.01 \pm 7.25$ \\
\hline TOM (\%) & $3.03 \pm 2.14$ & $2.41 \pm 1.83$ & $3.78 \pm 1.57$ & $2.81 \pm 1.19$ & $2.3 \pm 0.79$ & 2.04 & $3.65 \pm 2.22$ \\
\hline Mean $(\mu \mathrm{m})$ & $276.42 \pm 188.53$ & $715.07 \pm 843.18$ & $604.94 \pm 564.50$ & $347.2 \pm 153.59$ & $191.04 \pm 82.41$ & 174.02 & $324.79 \pm 352.05$ \\
\hline Sorting ( $\mu \mathrm{m})$ & $189.9 \pm 100.81$ & $359.83 \pm 353.21$ & $487.17 \pm 304.34$ & $337.63 \pm 161.46$ & $208.3 \pm 108.64$ & 122.67 & $315.13 \pm 323.78$ \\
\hline Gravel (\%) & $0.36 \pm 0.01$ & $22.55 \pm 0.38$ & $14.02 \pm 0.23$ & $1.83 \pm 0.03$ & $0.67 \pm 0.01$ & 0.03 & $5.53 \pm 0.14$ \\
\hline Sand (\%) & $84.08 \pm 0.18$ & $74.45 \pm 0.38$ & $77.05 \pm 0.20$ & $88.19 \pm 0.06$ & $76.06 \pm 0.17$ & 94.7 & $72.89 \pm 0.16$ \\
\hline Mud (\%) & $15.56 \pm 0.18$ & $2.99 \pm 0.02$ & $8.93 \pm 0.10$ & $9.98 \pm 0.07$ & $23.28 \pm 0.18$ & 5.27 & $21.58 \pm 0.14$ \\
\hline
\end{tabular}

aquaculture farms abundance increased and organic matter decreased with distance from culture centers [61]. A study of benthic ecosystem affected by a large salmon farm in a Norwegian fjord [20] found that in a 3 $\mathrm{km}$ transect the highest abundance, biomass and species richness was found $250 \mathrm{~m}$ from the center, and decreased at greater distances; these results follow the pattern proposed by the Pearson \& Rosenberg model [2]. Hargrave [55] reviewing published data established a series of empirical relationships including an inverse relationship between benthic macrofauna diversity and redox potential, as well as free dissolved sulfides. Borja et al. [27] studied seven fish farms, two bivalves farms and one mixed farm and found that the effect of organic enrichment around the centers generally extended for some $50 \mathrm{~m}$, and that the response of benthic biomass, abundance and species richness was highly variable and depended mainly on local hydrodynamics, sediment characteristics and the age and level of production of the farming center. This concurs with the results reported by Chamberlain [13], who found that the effects of organic matter are local, approximately $40 \mathrm{~m}$ from the bivalve farming centers and that biodeposits (i.e. true feces and uningested pseudofeces) accumulate up to $30 \mathrm{~m}$ from these centers in shallow $(10-15 \mathrm{~m})$ sites with lower hydrodynamic flow, while with higher hydrodynamic flow the deposits are dispersed up to $90 \mathrm{~m}$. Wilding \& Nickell [28] found similar results for bivalve farms, but in this case the distance at which the impact of biodeposits (shell-hash) was evident did not exceed $5 \mathrm{~m}$. The scope of the environmental effect of increased organic matter from farming centers depends on the dispersive capacity of the water column near the centers [13], which is influenced by advective transport of biodeposits and their redistribution on the seafloor [62], and by the location of the farming centers; there is less dispersion in shallow and low velocity sites $[61,63]$. Similar effects related to substrate change and biodiversity loss have been described in other parts of the world for mytilids and other mollusk farms such as oysters (e.g. [27, 29, 64]).

Various authors have reported that the main environmental impacts of salmon farming in Chile are related to physical-chemical changes to sediments and loss of benthic biodiversity $[19,59,65,66]$. Our study conducted in Caucahue Channel in winter conditions found 170 taxa belonging to different taxonomic groups with polychaetes, nematodes, mollusks and echinoderms the most important. At the spatial scale of the entire channel our findings indicate the presence of a high number of 
Table 5 Results of the marginal test for DISTLM analysis, using the BEST procedure for the Bray-Curtis resemblance matrix based on abundance (a) and biomass (b). Data were standardized and then fourth-root transformed. $P($ perm $)<0.05$ values are in bold. $\mathrm{BIC}=$ Bayesian Information Criterion. SS= Sum of Squares. For the DISTLM analysis we used all the data described in Table 3. In what follows we only present the first 10 best environmental variables according to BIC criteria. Res. d.f. $=45$ (Abundance and Biomass analysis)

\begin{tabular}{lllll}
\hline Variable & SS & Pseudo-F & P & BIC \\
\hline a) Abundance & & & & \\
Mean Grain Size $(\mathrm{mm})$ & 5944.1 & 2.655 & $\mathbf{0 . 0 0 3}$ & 368.20 \\
Sorting $(\mathrm{mm})$ & 5779.5 & 2.577 & $\mathbf{0 . 0 0 4}$ & 368.27 \\
Surface $\mathrm{pH}$ & 5393.8 & 2.396 & $\mathbf{0 . 0 0 6}$ & 368.45 \\
Seafloor pH & 4727.1 & 2.086 & $\mathbf{0 . 0 1 6}$ & 368.76 \\
\% Gravel & 4726.3 & 2.086 & $\mathbf{0 . 0 1 6}$ & 368.76 \\
TOM (\%) & 4654.6 & 2.053 & $\mathbf{0 . 0 1 6}$ & 368.80 \\
\% Mud & 4332.8 & 1.905 & $\mathbf{0 . 0 2 7}$ & 368.94 \\
Seafloor temperature $\left({ }^{\circ} \mathrm{C}\right)$ & 4312.6 & 1.896 & $\mathbf{0 . 0 3 0}$ & 368.95 \\
Depth (m) & 4155.9 & 1.824 & $\mathbf{0 . 0 3 2}$ & 369.03 \\
Surface temperature $\left({ }^{\circ} \mathrm{C}\right)$ & 3920.7 & 1.717 & 0.053 & 369.13 \\
b) Biomass & & & & \\
Mean Grain Size $(\mathrm{mm})$ & 7008.4 & 2.529 & $\mathbf{0 . 0 0 2}$ & 378.23 \\
Sorting (mm) & 6705.8 & 2.414 & $\mathbf{0 . 0 0 2}$ & 378.34 \\
TOM (\%) & 6413.2 & 2.303 & $\mathbf{0 . 0 0 3}$ & 378.45 \\
Surface pH & 6002.4 & 2.149 & $\mathbf{0 . 0 0 6}$ & 378.61 \\
\% Gravel & 5667.3 & 2.023 & $\mathbf{0 . 0 1 0}$ & 378.73 \\
Seafloor temperature $\left({ }^{\circ} \mathrm{C}\right)$ & 5522.6 & 1.969 & $\mathbf{0 . 0 1 2}$ & 378.79 \\
\% Mud & 5514.1 & 1.966 & $\mathbf{0 . 0 1 3}$ & 378.79 \\
Seafloor pH & 5498 & 1.960 & $\mathbf{0 . 0 1 3}$ & 378.80 \\
Depth (m) & 4496.5 & 1.591 & $\mathbf{0 . 0 5 5}$ & 379.17 \\
Surface temperature $\left({ }^{\circ} \mathrm{C}\right)$ & 4410.8 & 1.559 & $\mathbf{0 . 0 6 1}$ & 379.20 \\
\hline
\end{tabular}

Table 6 Best group of variables selected by DISTLM analysis, utilizing the BEST procedure and Bayesian Information Criterion (BIC) for resemblance matrixes based on (a) abundance and (b) biomass. BIC = Bayesian Information Criterion and RSS = Residual Sum of Squares

\begin{tabular}{|c|c|c|c|}
\hline BIC & RSS & No. of Var. & Variable Selection \\
\hline \multicolumn{4}{|c|}{ a) Abundance } \\
\hline 368.20 & 100,740 & 1 & Mean Grain Size (mm) \\
\hline 369.35 & 95,123 & 2 & Surface $\mathrm{pH}$, Sorting (mm) \\
\hline 371.20 & 91,155 & 3 & Surface $\mathrm{pH}$, Mean grain size $(\mathrm{mm})$, Sorting $(\mathrm{mm})$ \\
\hline 373.43 & 88,067 & 4 & Surface $\mathrm{pH}$, seafloor $\mathrm{pH}$, Mean grain size $(\mathrm{mm})$, Sorting $(\mathrm{mm})$ \\
\hline 375.73 & 85,207 & 5 & Depth $(\mathrm{m})$, Surface $\mathrm{pH}, \mathrm{TOM}(\%)$, Mean grain size $(\mathrm{mm})$, Sorting $(\mathrm{mm})$ \\
\hline \multicolumn{4}{|c|}{ b) Biomass } \\
\hline 378.23 & 124,710 & 1 & Mean Grain Size (mm) \\
\hline 379.61 & 118,320 & 2 & TOM (\%), Mean Grain Size (mm) \\
\hline 381.44 & 113,350 & 3 & TOM (\%), Sorting (mm) \\
\hline 383.42 & 108,920 & 4 & Seafloor pH, TOM (\%), Mean Grain Size (mm), Sorting (mm) \\
\hline 385.42 & 104,710 & 5 & Seafloor temperature $\left({ }^{\circ} \mathrm{C}\right)$, seafloor $\mathrm{pH}$, TOM $(\%)$, Mean grain size $(\mathrm{mm})$, Sorting $(\mathrm{mm})$ \\
\hline
\end{tabular}

species. However, species/taxon richness was low on average, in the range of 15 to 18 taxa in each sampling site, with slightly higher numbers in reference sites (REF). Few differences between sampling sites near and far from culture centers were recorded in the univariate diversity index at the ENV spatial scale of analysis (i.e. REF, SAL and MYT sites; See Fig. 3). However, the multivariate analysis indicated that benthic macrofauna are highly heterogeneous in both abundance and biomass at all the studied spatial scales (see Fig. 4). Although species richness per site was generally low and diversity was relatively homogeneous from the univariate perspective, the presence of species and their relative abundance were dissimilar at different spatial scales in Caucahue Channel (among sampling sites, between sites near and far from farming centers, among farming centers and between geographic areas in the channel, see Fig. 9). The high degree of spatial heterogeneity (high degree of beta diversity or spatial species turnover) determines the high number of total taxa identified. The global differences observed between sites near and far from farming centers (SAL and MYT versus REF sites), such as the displacement of centroids with respect to REF sites (See Fig. 4) suggest that the three types of environments present dissimilar ecological features. Two aspects should be considered in interpreting these results. First, this study does not seek to quantify the ecological conditions directly beneath fish cages or bivalve long-lines, but rather at sites near centers (between 5 and $100 \mathrm{~m}$ away), and at sites far from farming centers (between 500 and $3000 \mathrm{~m}$ away), that is, in the global context of the Caucahue Channel. Sites near and far from bivalve and salmonid farms can thus be considered distinct in terms of the relative abundance/biomass of macrofauna species. These differences were also found 


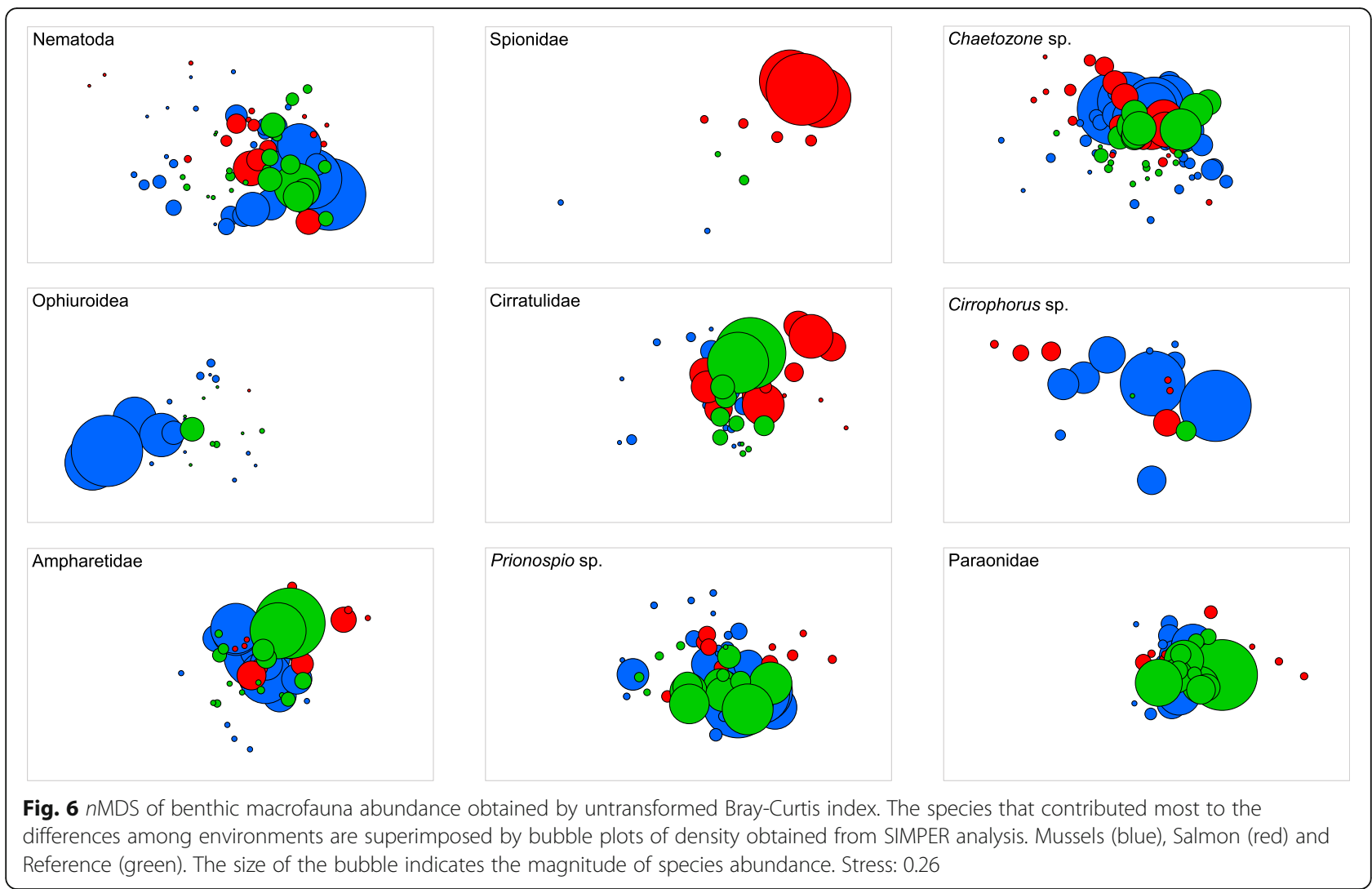

among the six farming centers and between these and the REF sites (See Fig. 4c, d and Fig. 9). A second aspect is related to how long this area has been used for aquaculture (approximately 30 years), which is sufficient time to structure resident populations that are stable under these conditions. The two aspects (i.e. distance from the centers of the sampling sites and the time that Caucahue Channel has been used for aquaculture) suggest that the macrofauna in the Caucahue Channel presents diverse very local populations, with significant spatial heterogeneity in abundance and biomass, which could result in some species acting as sources of organisms at this spatial scale, subsidizing areas in poorer environmental condition and linking macrofauna biodiversity from small spatial scales to the entire channel (see Fig. 9). Spatial abundance differentiation can be observed in Fig. 6 , which highlights nine taxa and/or main groups of organisms that indicate the high degree of spatial heterogeneity in species distribution and abundance. The overall community structure of Caucahue Channel should be compared to that immediately below the cages and long-lines to identify taxa and populations that benefit from or suffer disadvantages from aquaculture.

As described above, the distribution and abundance of benthic macrofauna has classically been associated with sediment characteristics [67, 68]. Abundance, biomass and species richness may reach very low values and defaunation when organic matter levels are extremely high $[2,69]$. Larger mean grain size of sediment is associated with lower organic matter content, given that larger grains allow more interstitial water, which in turn results in more oxygenated environments [70, 71]. Based on the DISTLM analysis (see Tables 5 and 6 for macrofauna abundance and biomass), our results indicate that mean grain size and \% TOM are the most important sediment variables in explaining the spatial dissimilarity in the benthic macrofauna community at different spatial scales (e.g. between REF sites and SAL and MYT sites), suggesting a benthic environment with heterogeneous input levels of organic matter coming from the surface. For example, SAL environments had smaller average grain size, while the other two environments (REF and MYT) had sediments in the entire size range (fine to coarse, but with higher average; See Table 4). While \%TOM values explained spatial differences among sites, the average percentages were generally not very high $(<4 \%$; See Table 4$)$. A heterogeneous input of organic matter, probably related to local circulation, could determine the mean grain size of sediments $[16-18,20$, $24,72]$ and probably the spatial heterogeneity in abundance and distribution of macrofauna species in Caucahue Channel. During autumn-winter conditions (17 April to 21 July 2011), [36] measured currents in Caucahue Channel using an acoustic Doppler current profiler 
Table 7 Output of SIMPER analyses obtained from abundance species data. In bold the most representative taxa for similarity within each group (MYT, SAL, REF sites)

\section{Group MYT}

Average similarity $=\mathbf{2 2 . 9 5}$

$\begin{array}{llllll}\text { Taxa } & \text { Av. Ab } & \text { Av. Sim } & \text { Sim/SD } & \text { Cont \% } & \text { Cum \% } \\ \text { Chaetozone sp. } & 1.54 & 3.2 & 0.86 & 13.94 & 13.94 \\ \text { Lumbrineris sp. } & 1.18 & 2.97 & 1.13 & 12.95 & 26.88 \\ \text { Nematoda } & 1.31 & 1.93 & 0.55 & 8.41 & 35.3 \\ \text { Amphipoda } & 0.83 & 1.41 & 0.55 & 6.14 & 41.44 \\ \text { Glycera sp. } & 0.78 & 1.21 & 0.53 & 5.27 & 46.71 \\ \text { Ninoe sp. } & 0.7 & 1.13 & 0.57 & 4.92 & 51.63 \\ \text { Prionospio sp. } & 0.82 & 0.92 & 0.39 & 4 & 55.63 \\ \text { Bivalvia } & 0.61 & 0.87 & 0.39 & 3.81 & 59.44 \\ \text { Paraonidae } & 0.69 & 0.67 & 0.33 & 2.92 & 62.35 \\ \text { Ampharetidae } & 0.65 & 0.61 & 0.3 & 2.64 & 64.99\end{array}$

Group SAL

Average similarity $=19.93$

\begin{tabular}{|c|c|c|c|c|c|}
\hline Taxa & Av. Ab & Av. Sim & Sim/SD & Cont \% & Cum \% \\
\hline Chaetozone sp. & 1.06 & 1.83 & 0.61 & 9.18 & 9.18 \\
\hline Cirratulidae & 0.99 & 1.8 & 0.43 & 9.02 & 18.19 \\
\hline Bivalvia & 0.84 & 1.58 & 0.62 & 7.95 & 26.14 \\
\hline Nematoda & 0.86 & 1.1 & 0.49 & 5.5 & 31.64 \\
\hline Amphipoda & 0.64 & 0.99 & 0.45 & 4.96 & 36.61 \\
\hline Ninoe sp. & 0.58 & 0.9 & 0.46 & 4.52 & 41.12 \\
\hline Paraonidae & 0.6 & 0.89 & 0.37 & 4.48 & 45.6 \\
\hline Sipunculidea & 0.55 & 0.77 & 0.37 & 3.86 & 49.46 \\
\hline Ampharetidae & 0.54 & 0.63 & 0.35 & 3.14 & 52.6 \\
\hline Lumbrineris sp. & 0.46 & 0.59 & 0.36 & 2.97 & 55.56 \\
\hline \multicolumn{6}{|l|}{ Group REF } \\
\hline \multicolumn{6}{|c|}{ Average similarity $=35.22$} \\
\hline Taxa & Av. Ab & Av. Sim & $\mathrm{Sim} / \mathrm{SD}$ & Cont \% & Cum \% \\
\hline Bivalvia & 1.82 & 5.48 & 2.02 & 15.56 & 15.56 \\
\hline Lumbrineris sp. & 1.08 & 2.73 & 1.15 & 7.76 & 23.32 \\
\hline Nematoda & 1.42 & 2.66 & 0.86 & 7.54 & 30.86 \\
\hline Ostracoda & 1.32 & 2.64 & 0.89 & 7.49 & 38.36 \\
\hline Chaetozone sp. & 1.31 & 2.51 & 0.84 & 7.12 & 45.47 \\
\hline Amphipoda & 1.11 & 2.4 & 0.89 & 6.8 & 52.28 \\
\hline Ninoe sp. & 1.04 & 1.99 & 0.96 & 5.66 & 57.93 \\
\hline Nephtys sp. & 0.76 & 1.47 & 0.59 & 4.18 & 62.12 \\
\hline Prionospio sp. & 1.09 & 1.42 & 0.55 & 4.03 & 66.14 \\
\hline Glycera sp. & 0.78 & 1.26 & 0.45 & 3.56 & 69.71 \\
\hline
\end{tabular}

(ADCP). They found (near Q11, See Fig. 1) that the mean flow of the total current located near the center of the channel was stratified, showing 2 layers (eastward at the surface and westward at the bottom) with speeds lower than $30 \mathrm{~cm} \mathrm{~s}^{-1}$. Along the channel tidal currents behaved approximately as a standing wave, explaining around $80 \%$ of the total variance. The cross-channel tidal currents explained between 40 and $60 \%$ of the total variance. In a time scale of days, residual currents from north to south have a mean flow near $6 \mathrm{~cm} \mathrm{~s}^{-1}$, favoring net transport in this direction depending on the fortnightly cycle (neap or spring time period). Sobarzo et al. [36] showed also that Caucahue Channel is dominated by tidal oscillatory flows most of the time, with a secondary transport flow north-south on a time scale of days. Therefore, it is expected that local circulation conditions strongly influence sedimentation rates at each sampling site, which are also influenced by the particulate organic matter in suspension derived from nearby aquaculture farms.

\section{Ecological status of Caucahue Channel}

The environmental quality of a marine area is generally estimated by the application of ecological criteria like abundance, biomass and species richness [2]. Benthic macrofauna is usually used in environmental quality studies because of their sensitivity and low mobility, among other life cycle characteristics; they integrate environmental conditions and changes that have occurred through time very effectively [10, 73, 74]. As noted above, the univariate indicators of diversity did not show major differences in Caucahue Channel, but the multivariate analysis did. Differences were found between the REF sites and the MYT and SAL sites in relation to abundance and total community biomass, with lower values for both variables at SAL sites (See Fig. 3). This can also be observed in Fig. 6 with the presence of dominant taxa in some SAL sites, mainly polychaetes of the families Spionidae and Cirratulidae. This suggests that the relative species abundance analysis at different spatial scales may be more useful than univariate indicators for detecting effects on the environment (i.e. assigning the relative abundance of each taxon to an ecological group). Borja et al. [27] concluded that a diverse set of indicators is needed to assess the environmental impact of aquaculture, including the AMBI as well as the characteristics of the culture center and the hydrodynamics of the area. The AMBI coefficient of the average values per site type (REF, MYT, and SAL; see Fig. 3) in Caucahue Channel globally indicated a slightly disturbed classification (Good Ecological Status according to [53]; AMBI <3.3; sensu [30]). However, analyzing the biotic index at a finer spatial scale (sampling or replicate sites), AMBI reached nearly 5 (with AMBI ranging from 0.9 to 3.6 for REF, 0.6 to 3.9 for MYT and 0.9 to 4.9 for SAL), that is, polluted/moderately disturbed (Moderate to Poor Ecological Status, according to [53]) (see also Fig. 8). It is interesting to note that the highest values of AMBI 
Table 8 Output of SIMPER analyses obtained from abundance species data. In bold the most representative taxa for dissimilarity among groups (MYT, SAL, REF sites)

\begin{tabular}{|c|c|c|c|c|c|c|}
\hline \multicolumn{7}{|l|}{ Groups MYT \& SAL } \\
\hline Average dissimilarity $=\mathbf{8 2 . 4 5}$ & MYT & SAL & & & & \\
\hline Taxa & Av. Ab & Av. Ab & Av. Diss & Diss/SD & Cont \% & Cum \% \\
\hline Chaetozone sp. & 1.54 & 1.06 & 3.11 & 1.18 & 3.77 & 3.77 \\
\hline Nematoda & 1.31 & 0.86 & 3.07 & 1.01 & 3.72 & 7.49 \\
\hline Cirratulidae & 0.43 & 0.99 & 2.48 & 0.88 & 3.01 & 10.5 \\
\hline Lumbrineris sp. & 1.18 & 0.46 & 2.22 & 1.29 & 2.69 & 13.19 \\
\hline Prionospio sp. & 0.82 & 0.48 & 2.12 & 0.84 & 2.57 & 15.76 \\
\hline Paraonidae & 0.69 & 0.6 & 2.04 & 0.96 & 2.48 & 18.24 \\
\hline Amphipoda & 0.83 & 0.64 & 2.03 & 1.08 & 2.46 & 20.7 \\
\hline Bivalvia & 0.61 & 0.84 & 2.03 & 1.04 & 2.46 & 23.16 \\
\hline Ampharetidae & 0.65 & 0.54 & 1.99 & 0.84 & 2.42 & 25.58 \\
\hline Glycera sp. & 0.78 & 0.41 & 1.79 & 1.02 & 2.17 & 27.75 \\
\hline \multicolumn{7}{|l|}{ Groups MYT \& REF } \\
\hline Average dissimilarity $=73.88$ & MYT & REF & & & & \\
\hline Taxa & Av. Ab & Av. Ab & Av. Diss & Diss/SD & Cont \% & Cum \% \\
\hline Nematoda & 1.31 & 1.42 & 2.98 & 1.12 & 4.03 & 4.03 \\
\hline Bivalvia & 0.61 & 1.82 & 2.78 & 1.52 & 3.77 & 7.79 \\
\hline Chaetozone sp. & 1.54 & 1.31 & 2.72 & 1.19 & 3.69 & 11.48 \\
\hline Prionospio sp. & 0.82 & 1.09 & 2.45 & 1 & 3.31 & 14.79 \\
\hline Ostracoda & 0.42 & 1.32 & 2.35 & 1.24 & 3.18 & 17.98 \\
\hline Paraonidae & 0.69 & 0.88 & 2.08 & 0.92 & 2.82 & 20.8 \\
\hline Ampharetidae & 0.65 & 0.85 & 2.01 & 0.99 & 2.72 & 23.52 \\
\hline Amphipoda & 0.83 & 1.11 & 1.99 & 1.15 & 2.7 & 26.22 \\
\hline Glycera sp. & 0.78 & 0.78 & 1.93 & 1.01 & 2.61 & 28.82 \\
\hline Caecum chilense & 0.51 & 0.63 & 1.9 & 0.72 & 2.57 & 31.39 \\
\hline \multicolumn{7}{|l|}{ Groups SAL \& REF } \\
\hline Average dissimilarity $=78.16$ & SAL & REF & & & & \\
\hline Taxa & Av. Ab & Av. Ab & Av. Diss & Diss/SD & Cont \% & Cum \% \\
\hline Nematoda & 0.86 & 1.42 & 2.77 & 1.08 & 3.55 & 3.55 \\
\hline Bivalvia & 0.84 & 1.82 & 2.7 & 1.28 & 3.45 & 7 \\
\hline Ostracoda & 0.17 & 1.32 & 2.67 & 1.26 & 3.41 & 10.41 \\
\hline Chaetozone sp. & 1.06 & 1.31 & 2.64 & 1.19 & 3.38 & 13.79 \\
\hline Cirratulidae & 0.99 & 0.76 & 2.6 & 0.9 & 3.33 & 17.12 \\
\hline Prionospio sp. & 0.48 & 1.09 & 2.28 & 1.02 & 2.91 & 20.03 \\
\hline Paraonidae & 0.6 & 0.88 & 2.13 & 0.98 & 2.73 & 22.76 \\
\hline Amphipoda & 0.64 & 1.11 & 2.11 & 1.21 & 2.7 & 25.46 \\
\hline Lumbrineris sp. & 0.46 & 1.08 & 1.93 & 1.29 & 2.47 & 27.94 \\
\hline Glycera sp. & 0.41 & 0.78 & 1.9 & 0.94 & 2.43 & 30.37 \\
\hline
\end{tabular}

are at sites near salmon farms. Three studies have previously reported AMBI values in Chilean Patagonia. In Aysén Fjord (an area used intensively for salmon aquaculture) and in Baker Fjord (an area not impacted by aquaculture) Quiroga et al. [75] found mean AMBI values from 2.7 to 4.0 and 1.5 to 2.4 , respectively. Working in the southwest area of Seno Reloncaví, Pino et al. [39] found mean AMBI values between 2.3 and 2.5 (near mussel long lines) and mean AMBI values between 1.9 and 3.4 in sampling reference sites. And Urbina [66], 
A)

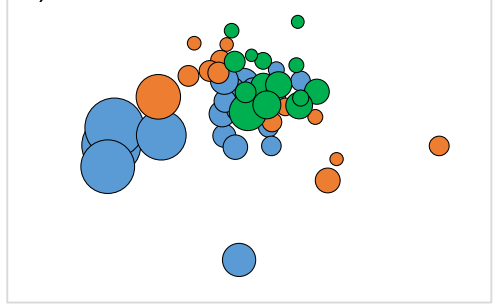

C)

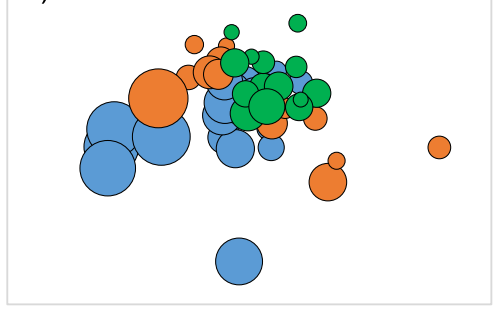

E)

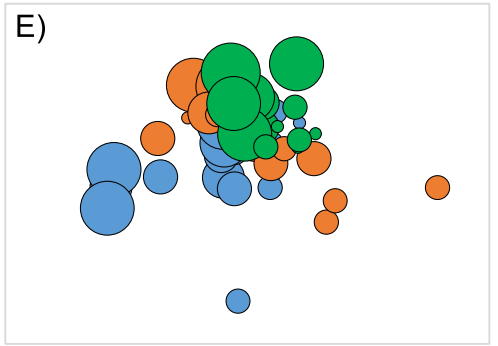

G)

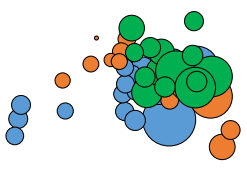

o
B)

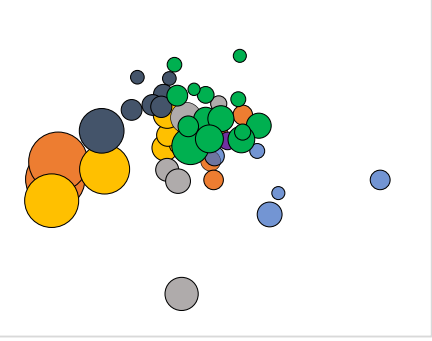

D)

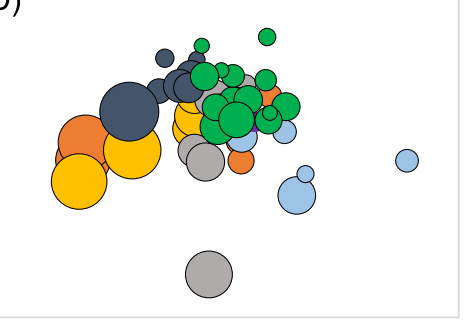

F)

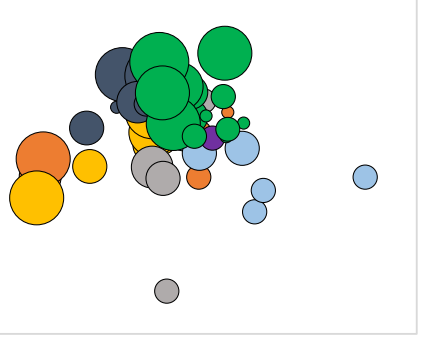

H)

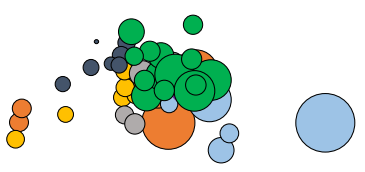

O

Fig. $7 \mathrm{nMDS}$ of the set of environmental variables (surface and sea floor of the water column and sediments) that contributed most to the differentiation found by the DISTLM analysis. TOM \% (a, b), Mean grain size (c, d), Sorting (e, $\mathbf{f})$, pH superficial ( $\mathbf{g}, \mathbf{h})$. ENV factor (left), MYT (light blue), SAL (orange) and REF (green); and CENTER factor (right); (Q1: orange, Q9: yellow, Q11: grey, Q2: light blue, Q6: purple, Q12: blue, REF: green). Stress: 0.17

analyzing exposed and protected areas in Reloncaví estuary and in Chiloé Island, finding mean AMBI values between 2.3 and 3.0 (near a salmonid farm) and between 0.1 and 2.0 in control sites. Our results indicated AMBI values ranging from 0.6 (near MYT ENV) to 4.9 (near SAL ENV), which is within the range of previously reported values, although with some scores above the maximum AMBI values reported previously for areas near salmon farms.

Evaluating environmental quality by assigning relative species abundance to ecological groups [30, 53], the impact of farming centers on the benthic communities located near the centers in Caucahue Channel (mainly SAL sites) is intermediate, characterized by the presence of Ecological Groups (EG) II to V. Some species/taxa are indicative of greater levels of disturbance, such as an abundance of opportunistic species like Capitella capitata (EG V; SAL sites) [2], and they may be dominant in areas directly beneath aquaculture centers [14]. In this study there was a lower proportion of Capitella sp. particularly at SAL sites, which were dominated by organisms of the families Cirratulidae [e.g. Chaetozone sp. (EG IV) and Spionidae (EG III)]. In MYT sites the dominant species were Ophiuroidea (EG II), nematodes (EG III), polychaetes of the family Cirratulidae like Chaetozone sp. (EG IV) and of the Spionidae family (EG III) like Prionospio sp. (EG II and IV). The polychaete families 

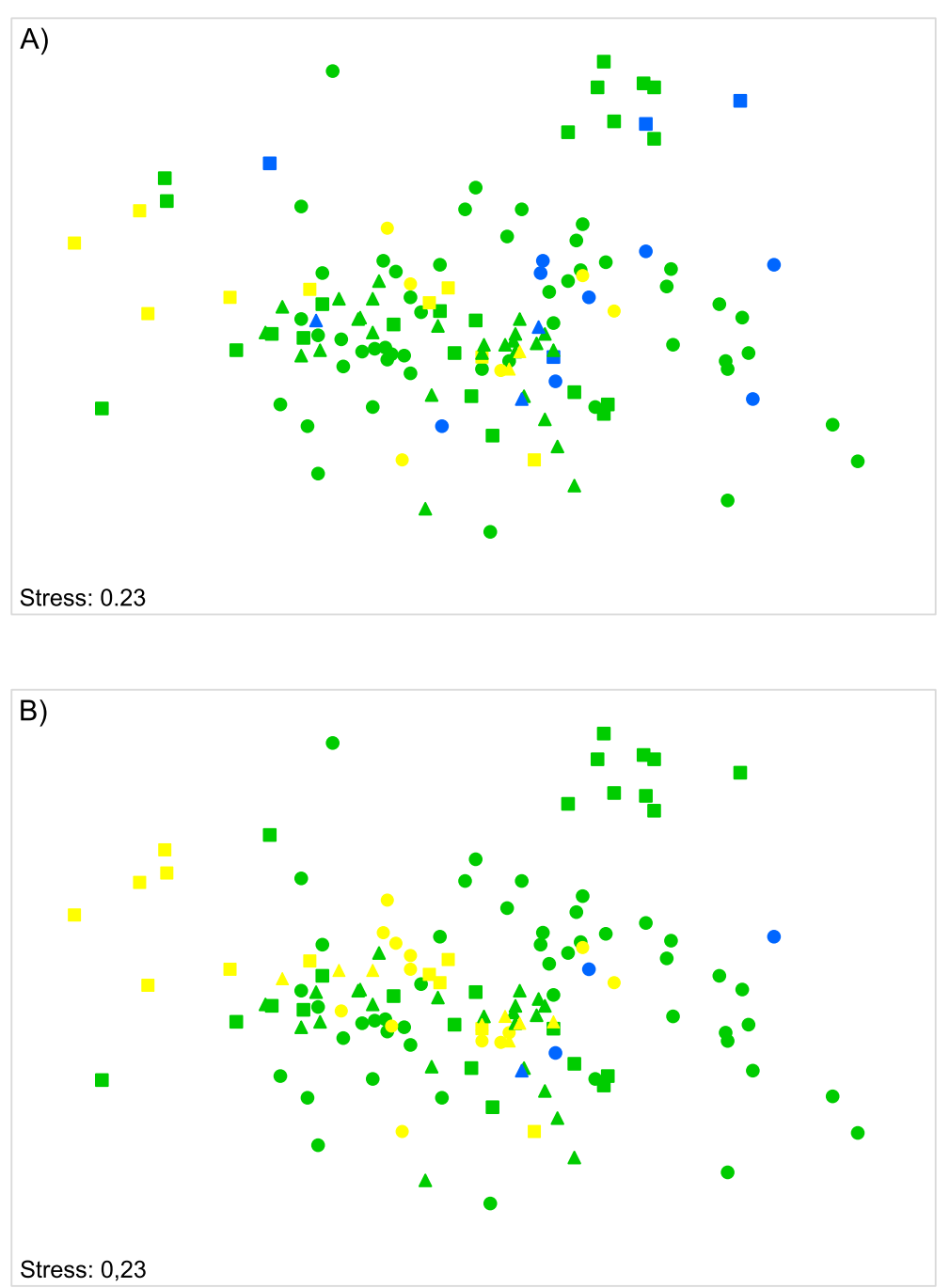

Fig. 8 Best (a) and poorest (b) ecological group assignment of species to obtain AMBI-1 and AMBI-2. AMBI values are superimposed in colors on each macrofauna replicate obtained in Caucahue Channel as represented by nMDS. The nMDS for abundance was obtained through the BrayCurtis index and fourth root transformed data. For the environment factor (ENV), circles represent mussel farms (MYT), squares represent salmon farms (SAL) and triangles represent reference sites (REF). The color indicates the level of disturbance according to the AMBI: undisturbed (blue), slightly disturbed (green) and moderately disturbed (yellow)

Cirratulidae (EG IV), Paraonidae (EG II), Ampharetidae (EG I and III) and Prionospio sp. (EG II and IV) were dominant at REF sites. The spatial dissimilarity of each of these species/taxa and their relative abundance/biomass is explained in the community in the winter, according to the DISTLM analysis, by the heterogeneity of the environmental variables mean grain size and \%TOM. Integrating the information obtained from the EG (e.g. AMBI) with the $n$ MDS analysis obtained from the relative abundance of the species (See Figs. 4, 6, 8), we characterized the benthic macrofauna community spatially at particular sites in Caucahue Channel. Integration of this type of ecological information (presence/abundance of taxon, ecological group and environmental variables) provides a robust quantitative tool to evaluate the degree of disturbance/pollution of benthic environments from small to large spatial scales (see Fig. 9).

Most research on the effects of aquaculture on benthic communities has been aimed at salmonid or mytilid production (see references above). In this analysis of Caucahue Channel we included both aquaculture activities. We determined under winter conditions that the macrofauna is highly dissimilar and associated with sediment structure. The level of perturbation is highly heterogeneous according to AMBI criteria, with sites ranging from undisturbed (Normal or High Ecological Status) to moderately disturbed (Moderate/Poor Ecological Status) according to benthic community health and site disturbance classification (sensu $[30,53])$. It would be useful to 


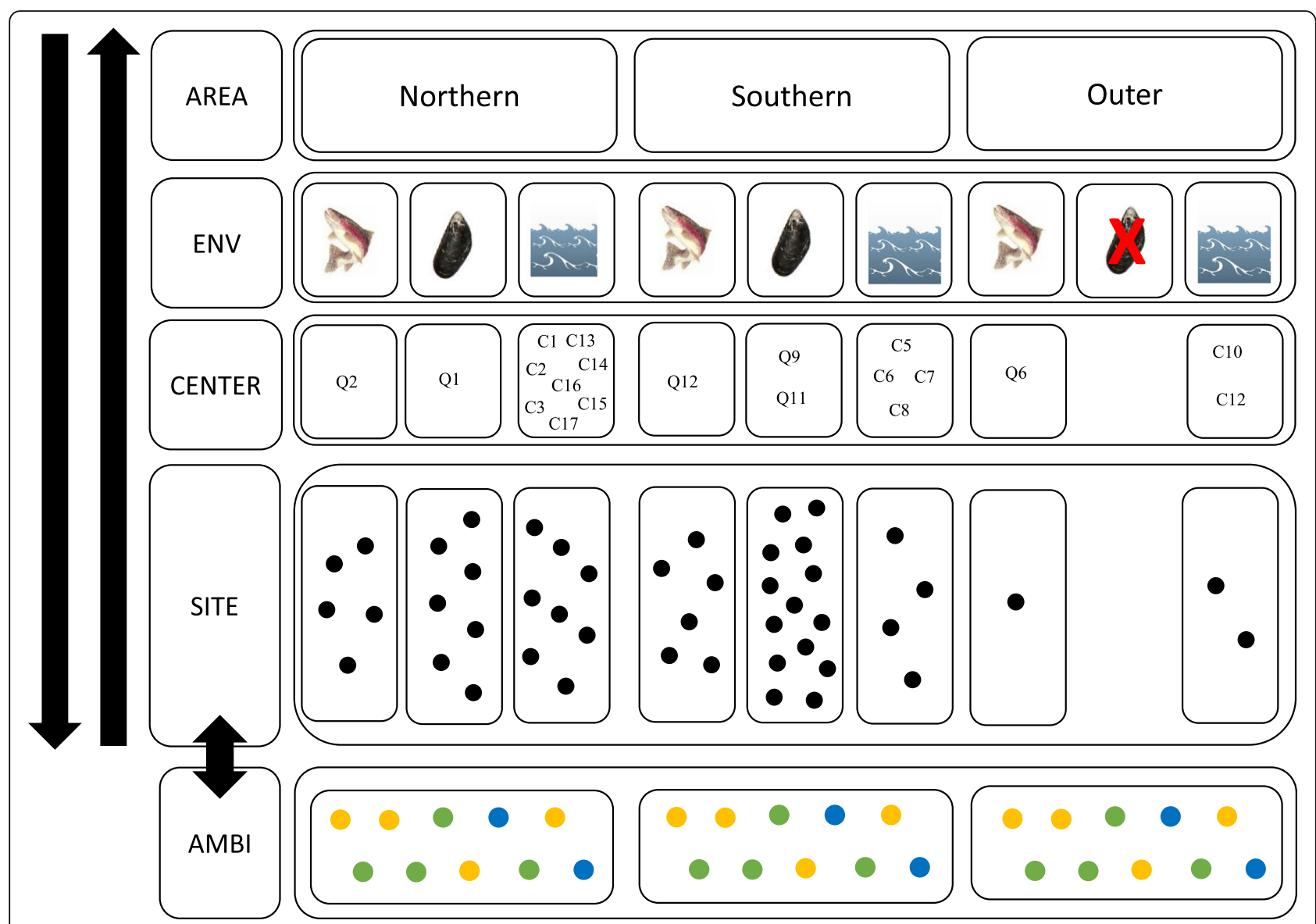

Fig. 9 Conceptual model for community dissimilarity of benthic macrofauna and for the ecological status of Caucahue Channel at different spatial scales of observation (i.e. factor of analysis). From top to bottom the factors are: AREA (northern, southern and outer), ENV (salmon, mussel and references), CENTER ( $\mathrm{Q}_{\mathrm{i}}$ to $\mathrm{C}_{\mathrm{i}}$ ) and SITE (each sampling site, represented with a black circle). From the PERMANOVA analysis significant differences were observed for each of these 4 factors between their different levels of comparison, which are indicated by areas with segmented lines. The ascending and descending black arrows represent hierarchy links present from the entire study AREA to the sampling sites (SITE) and vice versa. The black arrows pointing in two ways represent the relationship between the sampling sites and each of the replicates used for the estimations of ecological status using AMBI. The color circles represent a spatially explicit environmental traffic light to the smallest spatial scale possible (i.e., each replicate). For each of the factors studied in the Caucahue Channel (AREA, ENV and CENTER) it is possible to identify replicates (i.e. sampling SITES) ranging from undisturbed (blue circles) to moderately disturbed (yellow circles). For further details see the Discussion section

assess the classifications made in other seasons besides winter. For example, [76] found lower production of bivalve biodeposits in winter than in summer and autumn. Sampling in different seasons should provide greater certainty about the ecological impact of aquaculture farms in Caucahue Channel and other areas in the inner sea of Chiloe.

\section{Conclusions}

The main conclusions are (i) there was a high degree of spatial dissimilarity in benthic macrofauna and environmental variables in sediments and the water column among sampling sites, environmental types (near or far from farming centers) and between the northern and southern areas of the channel; (ii) sediment structure (mean grain size and \%TOM) correlated with community dissimilarities; and (iii) the AMBI index and the multivariate community-environment approximation allow defining the level of perturbation of a particular geographic area at different spatial scales, using the most detailed ecological information for the replicates or samples.

\section{Abbreviations}

ha: Hectares; ENV: Environment; CENTER: Farming center; SITE: Sampling site; AREA: Channel area; SAL: Salmonids; MYT: Mussels; REF: Reference; EG: Ecological Groups

\section{Acknowledgements}

We wish to thank A. Araneda, S. Miranda, S. Pérez, P. Constanzo and F. San Martín for their support in the fieldwork and sample analysis. We would also like to thank the captain and crew of the R/ Jürgen Winter of the Universidad Austral de Chile. 


\section{Authors' contributions}

EHM and RQ conceived and designed the field sampling. RE and PS analyzed macrofauna samples. EHM, RE, RV and MCK analyzed the data. EHM and $\mathrm{RQ}$ wrote the paper. All authors read and approved the final manuscript.

\section{Funding}

This research was funded by the Interdisciplinary Center for Aquaculture Research, INCAR (FONDAP-ANID 15110027). The funders had no role in the study design, data collection, analysis, decision to publish or preparation of the manuscript.

\section{Availability of data and materials}

The datasets used in the current study are available from the corresponding author on reasonable request.

\section{Ethics approval and consent to participate}

Not applicable.

\section{Consent for publication}

Not applicable.

\section{Competing interests}

The authors have declared that no competing interests exist.

\section{Author details}

'Interdisciplinary Center for Aquaculture Research (INCAR), Universidad de Concepción, O'Higgins, 1695 Concepción, Chile. ${ }^{2}$ Laboratorio de Investigación en Ecosistemas Acuáticos (LInEA), Facultad de Ciencias Naturales \& Oceanográficas, Universidad de Concepción, Concepción, Chile. ${ }^{3}$ Departamento de Oceanografía, Facultad de Ciencias Naturales \& Oceanográficas, Casilla 160-C, Universidad de Concepción, Concepción, Chile.

Received: 6 July 2020 Accepted: 13 January 2021

Published online: 28 January 2021

\section{References}

1. Forde J, Shin PK, Somerfield PJ, Kennedy RM. M-AMBI derived from taxonomic levels higher than species allows ecological status assessments of benthic habitats in new geographical areas. Ecol Indic. 2013;34:411-9.

2. Pearson T, Rosenberg R. Macrobenthic succession in relation to organic enrichment and pollution of the marine environments. Oceanogr Mar Biol Annu Rev. 1978;16:229-311.

3. Gray JS, Carr MR, Clarke KR, Green RH, Pearson TH, Rosenberg R, Warwick RM. Analysis of community attributes of the benthic macrofauna of Frierfjord/Langesundfjord and in a mesocosm experiment. Mar Ecol Prog Ser. 1988;46:151-65.

4. Carrasco FD, Gallardo VA. La contaminación marina y el valor de la macroinfauna en su evaluación y vigilancia: casos de estudio en el Litoral de Concepción, Chile. Biología Pesquera. 1989;18:15-27.

5. Levin LA, Boesch DF, Covish A, Dahm C, Erseus C, Ewel KC, Kneib RT, Moldenke A, Palmer MA, Snelgrove P, Strayer D, Weslawski JM. The function of marine critical transition zones and the importance of sediment biodiversity. Ecosystems. 2001;4:430-51.

6. Paul JF, Scott KJ, Campbell DE, Gentile JH, Strobel CS, Valente RM, Weisberg $\mathrm{SB}$, Holland AF, Ranasinghe JA. Developing and applying a benthic index of estuarine condition for the Virginian Biogeographic Province. Ecol Indic. 2001;1:83-99.

7. Dauvin JC. Paradox of estuarine quality: benthic indicators and indices, consensus or debate for the future. Mar Pollut Bull. 2007;55:271-81.

8. Díaz RJ, Solan M, Valente RM. A review of approaches for classifying benthic habitats and evaluating habitat quality. J Environ Manag. 2004;73:165-81.

9. Pinto R, Patricio J, Baeta A, Fath BD, Neto JM, Marques JC. Review and evaluation of estuarine biotic indices to assess benthic condition. Ecol Indic. 2009;9:1-25

10. Marques JC, Costa MJ, Elliott M. Introducing "assessing ecological quality in estuarine and coastal systems - management perspective". Estuar Coast Shelf Sci. 2012;112:1-3.

11. Borja A, Marín SL, Muxika I, Pino L, Rodríguez JG. Is there a possibility of ranking benthic quality assessment indices to select the most responsive to different human pressures? Mar Pollut Bull. 2015;97:85-94.
12. Beauchard O, Veríssimo H, Queirós AM, Herman PMJ. The use of multiple biological traits in marine community ecology and its potential in ecological indicator development. Ecol Indic. 2017;76:81-96.

13. Chamberlain J, Fernandes TF, Read P, Nickell TD, Davies IM. Impacts of biodeposits from suspended mussel (Mytilus edulis L.) culture on the surrounding surficial sediments. ICES J Mar Sci. 2001;58:411-6.

14. Callier M, McKindsey C, Desrosiers G. Multi-scale spatial variations in benthic sediment geochemistry and macrofaunal communities under a suspended mussel culture. Mar Ecol Prog Ser. 2007;348:103-15.

15. Ysebaert T, Hart M, Herman PMJ. Impacts of bottom and suspended cultures of mussels Mytilus spp. on the surrounding sedimentary environment and macrobenthic biodiversity. Helgol Mar Res. 2009;63:59-74.

16. Hall POJ, Anderson LG, Holby O, Kollberg S, Samuelsson M. Chemical fluxes and mass balances in a marine fish cage farm. I Carbon Marine Ecol Prog Ser. 1990;61:61-73.

17. Holmer M, Kristensen E. Impact of marine fish cage farming on metabolism and sulfate reduction of underlying sediments. Mar Ecol Prog Ser. 1992;80: 191-201.

18. Karakassis I, Tsapakis M, Hatziyanni E, Papadopoulou KN, Plaiti W. Impact of cage farming of fish on the seabed in three Mediterranean coastal areas. ICES J Mar Sci. 2000:57:1462-71.

19. Soto $D$, Norambuena $F$. Evaluation of salmon farming effects on marine systems in the inner seas of southern Chile: a large-scale mensurative experiment. J Appl Ichthyol. 2004;20:493-501.

20. Kutti T, Ervik A, Hansen PK. Effects of organic effluents from a salmon farm on a fjord system. I. Vertical export and dispersal processes. Aquaculture. 2007;262:367-81.

21. Keeley NB, Forrest BM, Crawford C, Macleod CK. Exploiting salmon farm benthic enrichment gradients to evaluate the regional performance of biotic indices and environmental indicators. Ecol Indic. 2012;23:453-66.

22. Ye LX, Ritz DA, Fenton GE, Lewis ME. Tracing the influence on sediments of organic waste from a salmonid farm using stable isotope analysis. J Exp Mar Biol Ecol. 1991;145:161-74

23. Karakassis I, Tsapakis M, Hatziyanni E. Seasonal variability in sediment profiles beneath fish farm cages in the Mediterranean. Mar Ecol Prog Ser. 1998;162:243-52.

24. Kutti T, Ervik A, Høisæter T. Effects of organic effluents from a salmon farm on a fjord system. III. Linking deposition rates of organic matter and benthic productivity. Aquaculture. 2008;282:47-57.

25. Hargrave BT, Duplisea DE, Pfeiffer E, Wildish DJ. Seasonal changes in benthic fluxes of dissolved oxygen and ammonium associated with marine cultured Atlantic salmon. Mar Ecol Prog Ser. 1993;96:249-57.

26. Sanz-Lázaro C, Marín A. Assessment of Finfish Aquaculture Impact on the Benthic Communities in the Mediterranean Sea. Dyn Biochem Process Biotechnol Mol Biol. 2008;2(Special Issue 1):21-32.

27. Borja A, Rodríguez JG, Black K, Bodoy A, Emblow C, Fernandes TF, Forte J, Karakassis I, Muxika I, Nickell TD, Papageorgiou N, Pranovi F, Sevastou K, Tomassetti $P$, Angel D. Assessing the suitability of a range of benthic indices in the evaluation of environmental impact of fin and shellfish aquaculture located in sites across Europe. Aquaculture. 2009;293:231-40.

28. Wilding TA, Nickell TD. Changes in Benthos Associated with Mussel (Mytilus edulis L). Farms on the West-Coast of Scotland. PLoS One. 2013;8(7):e68313. https://doi.org/10.1371/journal.pone.0068313.

29. Gallardi D. Effects of bivalve aquaculture on the environment and their possible mitigation: a review. Fish Aquac J. 2014;5:105. https://doi.org/10. 4172/2150-3508.1000105

30. Borja A, Franco J, Pérez V. A marine biotic index to establish the ecological quality of soft-bottom benthos within European estuarine and coastal environments. Mar Pollut Bull. 2000;40:1100-14.

31. Borja A, Muxica I. Guidelines for the use of AMBI (AZTI's marine biotic index) in the assessment of the benthic ecological quality. Mar Pollut Bull. 2005;50: 787-9.

32. Borja A, Muxika I, Franco J. The application of a marine biotic index to different impact sources affecting soft-bottom benthic communities along European coasts. Mar Pollut Bull. 2003;46:835-45.

33. Grall J, Glémarec M. Using biotic indices to estimate macrobenthic community perturbations in the Bay of Brest. Estuar Coast Shelf Sci. 1997; 44(suppl. A):43-53.

34. Borja A, Marín S, Nuñez R, Muxika I. Is there a significant relationship between the benthic status of an area, determined by two broadly-used indices, and best professional judgment? Ecol Indic. 2014;45:308-12. 
35. Riquelme R, Campos P, Troncoso A, Salamanca M, Sobarzo M, Agurto C, Bravo L. Evaluación de las agrupaciones de concesiones de acuicultura implementadas en la industria del cultivo del salmón en Chile en base a zonas estimadas por modelos de trayectoria de partículas. Mecánica Computacional. 2013;32:2795-810.

36. Sobarzo M, Bravo L, Iturra C, Troncoso A, Riquelme R, Campos P, Agurto C. Hydrodynamics of a channel occupied by the aquaculture industry in southern Chile: implications for connectivity between farms. Aquaculture Environ Interact. 2018;10:291-307.

37. Informe Ambiental Quemchi. Estudios previos plan regulador comunal de Quemchi, Región de Los Lagos; 2014. p. 81.

38. Hernández-Miranda E, Veas R, Krautz MC, Hidalgo N, San Martín F, Quiñones RA. Bio-Indicadores de contaminación marina costera y filtros de exclusión de organismos en sistemas de captación de agua de mar. En "Programas de monitoreo del medio marino costero: diseños experimentales, muestreos, métodos de análisis y estadística asociada". Juan C. Castilla, José M. Fariña y Andrés Camaño (Eds). Ediciones Universidad Católica. Santiago, Chile; 2020. p. 269-88.

39. Pino L, Marín SL, Núñez R. Indicadores bióticos y fracción de tamaños en la definición de la macrofauna. Lat Am J Aquat Res. 2015;43:329-36.

40. Buchanan JB. Measurements of the physical and chemical environment. In: Holme NA, Mclntyre AD, editors. Methods for the study of marine benthos, IBP Handbook N 16. Oxford: Blackwell; 1971. p. 30-52.

41. Blott SJ, Pye K. GRADISTAT: a grain size distribution and statistics package for the analysis of unconsolidated sediments. Earth Surf Process Landf. 2001; 26:1237-48

42. Byers $S$, Mills $E$, Stewart P. A comparison of methods of determining organic carbon in marine sediments, with suggestion for a standard method. Hydrobiologia. 1978;58:43-7.

43. Anderson $M$, Ellingsen $K$, McArdle B. Multivariate dispersion as a measure of beta diversity. Ecol Lett. 2006;9:683-93.

44. Anderson M. A new method for non-parametric multivariate analysis of variance. Austral Ecol. 2001;26:32-46.

45. Anderson M. PERMANOVA: a FORTRAN computer program for permutational multivariate analysis of variance. New Zealand: Department of Statistics, University of Auckland; 2005. p. 24.

46. Clarke KR, Gorley RN. PRIMER v6: user manual/tutorial. Plymouth: PRIMER-E; 2006.

47. Anderson M, Gorley RN, Clarke KR. PERMANOVA+ for PRIMER: guide to software and statistical methods. Plymouth: PRIMER-E; 2008.

48. McArdle BH, Anderson MJ. Fitting multivariate models to community data: a comment on distance-based redundancy analysis. Ecology. 2001; 82:290-7.

49. Clarke KR, Warwick RM. Change in marine communities: an approach to statistical analysis and interpretation. 2nd ed. Plymouth: PRIMER-E; 2001.

50. Muxika I, Borja A, Bald J. Using historical data, expert judgment and multivariate analysis in assessing reference conditions and benthic ecological status, according to the European water framework directive. Mar Pollut Bull. 2007;55:16-29.

51. Borja A, Mader J, Muxika I. Instructions for the use of the AMBI index software (version 5.0). Rev Invest Marina AZTI-Tecnalia. 2012;19(3):71-82.

52. Teixeira H, Weisberg SB, Borja A, Ranasinghe JA, Cadien DB, Velarde RG, Lovell LL, Pasko D, Phillips CA, Montagne DE, Ritter KJ, Salas F, Marques JC. Calibration and validation of the AZTI's marine biotic index (AMBI) for Southern California marine bays. Ecol Indic. 2012;12:84-95.

53. Muxika I, Borja A, Bonne W. The suitability of the marine biotic index (AMBI) to new impact sources along European coasts. Ecol Indic. 2005;5:19-31.

54. Maes J, Liquete C, Teller A, Erhard M, Paracchini ML, Barredo Jl, Grizzetti B, Cardoso A, Somma F, Petersen JE, Meiner A, Gelabert ER, Zal N, Kristensen P, Bastrup-Birk A, Biala K, Piroddi C, Egoh B, Degeorges P, Fiorina C, SantosMartín F, Naruševičius V, Verboven J, Pereira HM, Bengtsson J, Gocheva K, Marta-Pedroso C, Snäll T, Estreguil C, San-Miguel-Ayanz J, Pérez-Soba M, Grêt-Regamey A, Lillebø Al, Malak DA, Condé S, Moen J, Czúcz B, Drakou EG, Zulian G, Lavalle C. An indicator framework for assessing ecosystem services in support of the EU Biodiversity Strategy to 2020. Ecosystem Serv. 2016;17:14-23.

55. Hargrave BT. Empirical relationships describing benthic impacts of salmon aquaculture. Aquaculture Environ Interact. 2010;1:33-46.

56. Holmer M, Wildish D, Hargrave B. Organic Enrichment from Marine Finfish Aquaculture and Effects on Sediment Biogeochemical Processes. In: Hargrave B, editor. Environmental Effects of Marine Finfish Aquaculture. Berlin, Heidelberg: Springer Berlin Heidelberg; 2005. p. 181-206.
57. Keeley NB, Macleod CK, Hopkins GA, Forrest BM. Spatial and temporal dynamics in macrobenthos during recovery from salmon farm induced organic enrichment: when is recovery complete? Mar Pollut Bull. 2014;80: 250-62.

58. Barrett LT, Swearer SE, Dempster T. Impacts of marine and freshwater aquaculture on wildlife: a global meta-analysis. Rev Aquac. 2019;11:1022-44.

59. Quiñones RA, Fuentes ME, Montes RM, Soto D, León-Muñoz J. Environmental issues in Chilean salmon farming: a review. Rev Aquac. 2019; 11(2):375-402

60. Weitzman J, Steeves L, Bradford J Filgueira R. Far-Field and Near-Field Effects of Marine Aquaculture. In World Seas: an Environmental Evaluation (2nd Edition) Volume III: Ecological Issues and Environmental Impacts, Ed. 2 (pp. 197-220). Amsterdam: Elsevier Ltd.

61. Weise AM, Cromey CJ, Callier MD, Archambault P, Chamberlain J, McKindsey CW. Shellfish-DEPOMOD: Modelling the biodeposition from suspended shellfish aquaculture and assessing benthic effects. Aquaculture. 2009;288: 239-53.

62. Giles H, Broekhuizen N, Bryan KR, Pilditch CA. Modelling the dispersal of biodeposits from mussel farms: the importance of simulating biodeposit erosion and decay. Aquaculture. 2009;291:168-78.

63. Crawford CM, Macleod CKA, Mitchell IM. Effects of shellfish farming on the benthic environment. Aquaculture. 2003:224:117-40.

64. Mckindsey CW, Archambault P, Callier MD, Olivier F. Influence of suspended and off-bottom mussel culture on the sea bottom and benthic habitats: a review. Can J Zool. 2011;89:622-46.

65. Buschmann $A H$, Riquelme VA, Hernández-González MC, Varela D, Jiménez JE, Henríquez LA, Vergara PA, Guíñez R, Filún L. A review of the impacts of salmonid farming on marine coastal ecosystems in the Southeast Pacific. ICES J Mar Sci. 2006;63:1338-45.

66. Urbina M. Temporal variation on environmental variables and pollution indicators in marine sediments under sea Salmon farming cages in protected and exposed zones in the Chilean inland Southern Sea. Sci Total Environ. 2016:573:841-53.

67. Etter RJ, Grassle JF. Patterns of species diversity in the deep sea as a function of sediment particle size diversity. Nature. 1992;360:576-8.

68. Martins R, Sampaio L, Rodrigues AM, Quintino V. Soft-bottom Portuguese continental shelf polychaetes: Diversity and distribution. J Mar Syst. 2013; 123-124:41-54

69. McNally WH, Mehta AJ. Sediment Transport and Deposition in Estuaries (Sample Chapter). In: Encyclopedia of Life Support Systems (EOLSS): Coastal Zones and Estuaries; 2004. Retrieved from http://www.eolss.net/samplechapters/c09/E2-06-01-04.pdf.

70. Ziebis W, Huettel M, Forster S. Impact of biogenic sediment topography on oxygen fluxes in permeable seabeds. Mar Ecol Prog Ser. 1996;140:227-37.

71. Janssen $F$, Huettel M, Witte U. Pore-water advection and solute fluxes in permeable marine sediments (II): benthic respiration at three sandy sites with different permeabilities (German bight, North Sea). Limnol Oceanogr. 2005;50(3):779-92.

72. Findlay RH, Watling L, Mayer LM. Environmental impact of salmon net-pen culture on marine benthic communities in Maine: a case study. Estuaries. 1995;18:145-79.

73. Dauer D. Biological criteria, environmental health and estuarine macrobenthic community structure. Mar Pollut Bull. 1993;26:249-57.

74. Salas F, Marcos C, Neto JM, Patrıcio J, Pérez-Ruzafa A, Marques JC. Userfriendly guide for using benthic ecological indicators in coastal and marine quality assessment. Ocean Coast Manag. 2006;49:308-31.

75. Quiroga E, Ortiz P, Reid B, Gerdes D. Classification of the ecological quality of the Aysen and baker fjords (Patagonia, Chile) using biotic indices. Mar Pollut Bull. 2013;68:117-26.

76. Hatcher A, Grant J, Schofield B. Effects of suspended mussel culture (Mytilus spp.) on sedimentation, benthic respiration and sediment nutrient dynamics in a coastal bay. Mar Ecol Prog Ser. 1994;115:219-35.

\section{Publisher's Note}

Springer Nature remains neutral with regard to jurisdictional claims in published maps and institutional affiliations. 